\title{
PARAMETRIC STUDY OF STEEL BEAMS TEMPERATURE IN COMPARTEMENT SUBJECTED TO REAL FIRE SCENARIOS
}

\author{
Khaled Ahmed Mahmoud \\ Kama_elsadek@yahoo.com \\ Dr. Eng., Private Consultant Civil Engineer, Assiut, Egypt
}

(Received July 22, 2010 Accepted October 5, 2010)

\begin{abstract}
In this article, the behavior of a compartment under real fire scenarios has been studied.The fire model OZONE is employed in order to predict the temperature development in the fire compartment. The influence of different parameters such as fire area, active measures, opening factor, compartment area, compartment height, compartment rectangularity, type and boundary wall thickness, presence of protection, shape of protection and type of protection on the steel beams inside the compartment has been investigated. The fire resistance for the steel beams was calculated and a comparison between the results was carried out.
\end{abstract}

KEYWORDS: Fire compartment; OZONE; Steel beam; Fire resistance

\section{1- INTRODUCTION}

Traditionally, the fire resistance of load-bearing structures is assessed by considering the behavior of single structural components, rather than the composite behavior of a complete structure. In the traditional approach, the elements which are considered to be critical are isolated from the whole structure. The fire resistance is assessed on the basis of the behavior under fire of this isolated element. This assessment could either be based on an existing design rule. Or, when such design rule is not available, the isolated element is taken to a furnace for fire testing. In order to perform the fire test, the single element is incorporated in a test rig and thus subjected to a certain set of boundary conditions. Also, a certain schematized loading is applied. By this approach, the real fire behavior of a whole structure is not taken into account properly.

Also in the single structural component approach, strongly schematized, standard fire conditions are taken into account. Whereas in reality, fire conditions can be quite different from case to case. Depending on various parameters, the fire development in a compartment can differ significantly, both in the time and the temperature regime. This is not taken into account in the standard approach for fire resistance testing.

The standard fire curve describes the variation of the temperature of the fire gases within a standard furnace but bears little resemblance to any natural fire curve. It takes no account of the different thermal exposures which result from different compartment geometries, ventilation conditions, fire loads and compartment boundary materials [1]. With the t-equivalence approach the heating effect in a compartment is calculated based on real compartment fire behavior and that heating is related back to the standard furnace test. However, the energy and mass balance equations for the fire compartment can be used to determine the actual thermal exposure and fire duration. This is known as the natural fire method. This method allows the combustion 
characteristics of the fire load, the ventilation effects and the thermal properties of the compartment enclosure to be considered. It is the most rigorous means of determining fire duration. This is not related in any way to the standard fire resistance test and represents the real fire duration, once flashover has occurred. Local fires can only be determined by natural fire curves.

Standard fire tests are conducted worldwide and are defined by the International Standards Organization in ISO 834 [2]. Standard fire tests in the United Kingdom are defined in BS 476 [3]. The first ASTM standard for fire resistance testing, C19 (now E119), was published in 1918 [4]. The ASTM standard fire curve is prescribed by a series of points rather than an equation but is almost identical to the British Standard curve.

The fire resistance test has been criticized by many researchers over many years. One major criticism is that the temperatures of the furnace gases do not represent the fire exposure to the element under test because the fire exposure is dependent on the physical properties of the furnace. The construction shape influences the degree of turbulence and thus convective heat transfer. However most significantly the thermal inertia of the wall linings affect the radiative heat transfer to the element under test [5]. Indeed Drysdale [6] suggests that no two furnaces will give the same fire exposure. Furnaces also differ in the fuel adopted. They may be gas or oil fired.

Another criticism of the standard temperature-time curve is that it bears little resemblance to a real fire temperature-time history. It has no decay phase and as such does not represent any real fire although Malhotra [4] reports that it is designed to typify temperatures experienced during the post-flashover phase of most fires. Figure (1) illustrates the temperature-time histories of "real" fires, of varying fire load and ventilation, together with the standard curve. The fire load is in $\mathrm{kg} / \mathrm{m}^{2}$ and the ventilation is a fraction of one wall e.g. $15(1 / 2)$ corresponds to a fire load of $15 \mathrm{~kg} / \mathrm{m}^{2}$ and ventilation equal to half of one wall [6]. This highlights that the standard curve does not represent many real fires in the post-flashover phase or otherwise.

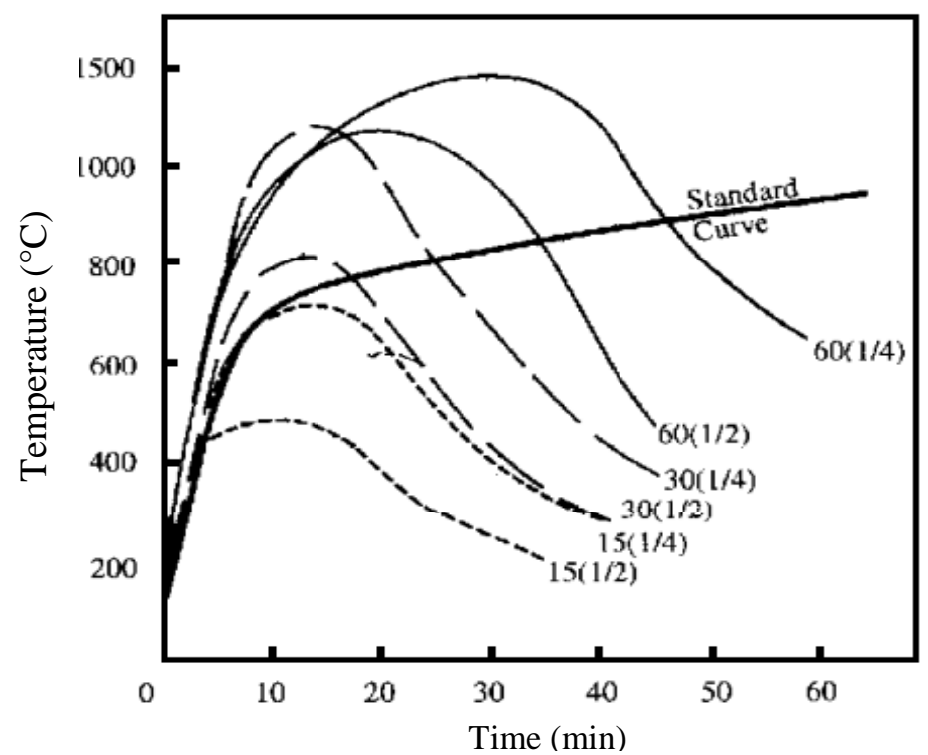

Fig. (1): Comparison of the standard fire curve and real temperature-time histories. 
When dealing with realistic fire scenarios, the fire safety design is based on physically determined thermal actions. In contrast with conventional fire design, parameters like ignition source, the amount and type of fuel, the size of the enclosure, the amount of ventilation, the growth rate and the rate of heat release play an important role in the fire design. The specification of appropriate and realistic design fire scenarios is a crucial aspect of fire safety design. The assumptions made with regard to these factors have a major influence on the thermal conditions within a compartment and have a significant impact on the fire design. The design fire scenarios used for the analysis/development of a building fire have to be deduced from all the possible fire scenarios. In most buildings, the number of possible fire scenarios is infinite and need to be reduced. Only credible worst case fire scenarios should be studied. If the design fire scenarios are chosen, a number of fire models are available to calculate the thermal actions.

The compartment fire process can be described by three distinct phases, the pre-flashover fire, the fully-developed fire (or post-flashover fire) and the cooling phase. There is a rapid transition stage called flashover between the pre-flashover and fully developed fire. This is shown in Fig. (2) [6] which illustrates the whole process in terms of heat released against time. While still small (during the growth phase) the compartment fire will behave as it would in the open. As it grows the confinement of the compartment begins to influence its behavior. If there is sufficient fuel and ventilation the fire will develop to flashover and its maximum intensity, when all combustible surfaces are burning. If the fire is extinguished before flashover or if the fuel or ventilation is insufficient there will only be localized damage. Post-flashover the whole enclosure and its contents will be devastated. Structural damage and fire spread beyond the compartment of origin is also likely unless the fire is in a fire rated enclosure.

During the last decades, many analytical and experimental researches have been carried out to investigate the behavior of compartments and steel structures and under fire [7, 8, 9, 10, 11, and 12]. A comprehensive survey for fire and smoke models can be found in [13]. The results are different from case to case according to the assumptions and test circumstances.

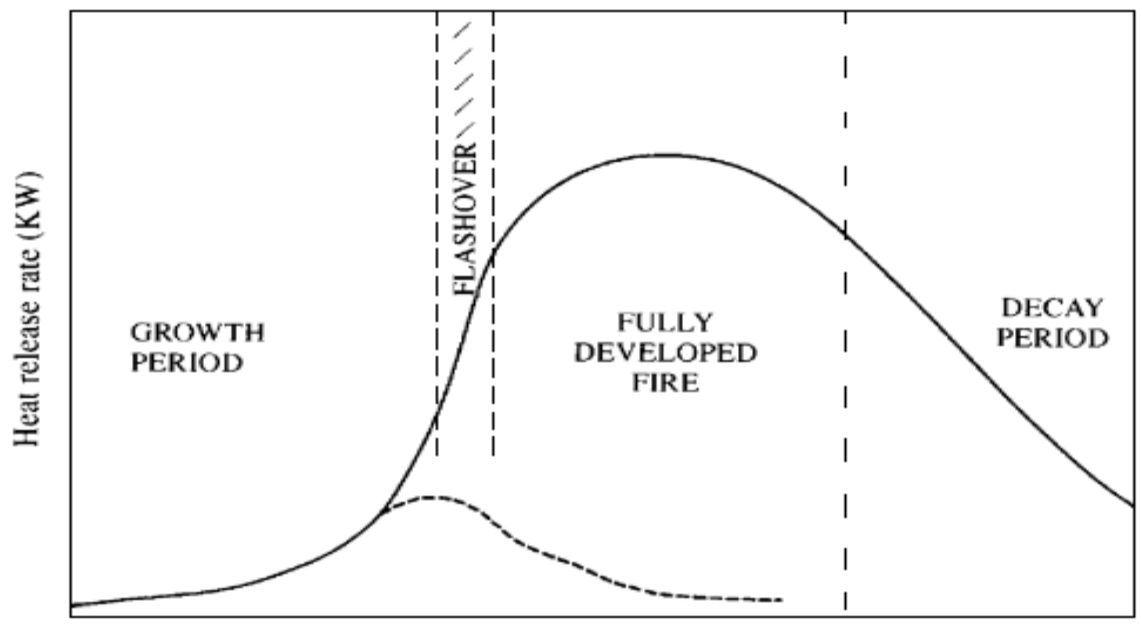

Time

Fig. (2): The course of a well-ventilated compartment fire [66] 
Y. Tsuchiya and K. Sumi [14] studied the behavior of fire in an enclosure. They found that smaller fuel packages with increased surface area produce higher maximum temperatures but large fuel packages result in longer decay periods. Decay periods vary with the size of the fuel rather than opening factor or wall material properties.

Most models for compartment fires are tested on regular shaped compartments with small openings. Buchanan [15] states that compartments with floor areas up to $6 \mathrm{~m}$ x $6 \mathrm{~m}$ can be modeled with confidence. This seems conservative although researchers have always recognized that the validity of compartment models to large, long or tall compartments is questionable.

The most comprehensive analysis of compartment fires in long enclosures has been conducted by Thomas and Bennetts. [16] They conducted an experimental program designed to investigate the enclosure shape and opening width and their effect on the burning rate. Fire tests were conducted on enclosures $1500 \mathrm{~mm}$ by $600 \mathrm{~mm}$ by $300 \mathrm{~mm}$ high with vents of several widths. The main conclusions were that the fuel mass loss rates of fires in long and wide enclosures differ markedly if the width of the ventilation opening is less than the full width of the enclosure.

Kirby et al [17] conducted a series of 6 experiments on long compartments. The ventilation was provided by a window at one end of the compartment (short elevation). Tests were conducted with each of the four ventilation levels, 1, 1/2, 1/4 and $1 / 8$ of the end wall. The wood cribs were situated in lines over the depth of the compartment. The cribs furthest from the ventilation were lit first. The fire moved towards the ventilation igniting each line of cribs. At the same time the cribs at the back of the compartment ceased burning. The cribs near the vents burned until there was no fuel left then the fire moved back over the cribs again towards the rear of the compartment. This pattern of behavior was observed in all six tests. It was also observed by Thomas and Bennetts [16]. The behavior of compartment fires in long compartments is still not well understood however it is clear the behavior is quite different from our understanding of "regular" compartment fire dynamics.

Fire protection of steel can be achieved by three methods: insulating the element with spray material or board type protection, shielding or hollow sections can filled with concrete or liquid to form a heat sink. Traditional fire protection materials have included concrete, blockwork and plasterboard. Until the late 1970s, concrete was the most common form of fire protection for steelwork. The major disadvantages are cost, the increase in weight to the structure and the time it takes to apply on site. Nowadays modern lightweight sprays and boards have replaced these.

Passive fire protection materials insulate the structure from high temperatures. The insulation materials can be classified as non-reactive (e.g. boards and sprays) or reactive (e.g. intumescent coatings).

Boards are fixed dry usually to columns. Beams are more commonly protected with spray materials. The main advantages of spray coverings are, they are cheap and they easily cover complex details. However application is wet and may delay other work on site.

Site applied intumescent coatings are paint like substances or mastics. Paints are stable at low temperatures but swell at around $200^{\circ} \mathrm{C}$ to provide a charred layer of low conductivity material to insulate the steel. Mastics are applied using a trowel or as a heavy duty spray. They form a thick protective coating which is impervious at 
ambient and at high temperatures. They can be hard and ceramic in appearance or soft and tar like. The main advantage of intumescents paints over other protection products are their appearance. However they are more expensive than sprays and boards, application is wet and there is a limit to the fire resistance periods they can achieve typically 30 and 60 minutes. [18] A limited number provide longer fire resistance periods but the cost increases considerably. Paints are also applied off-site.

\section{NATURAL FIRE MODELLING}

Regarding the methods for assessing the fire severity, different levels of fire calculation methods are relevant to the various stages of fire development. When a fire is initiated, it is localized within a compartment and, according to the characteristics of the compartment and of the fire load, it can remain localized or becomes generalized to the whole compartment as shown in Fig. (3).

In many cases of small compartments or small opening regarding the compartment size, the fire develops into to a fully developed fire.

$\theta(\mathrm{t})$ uniform

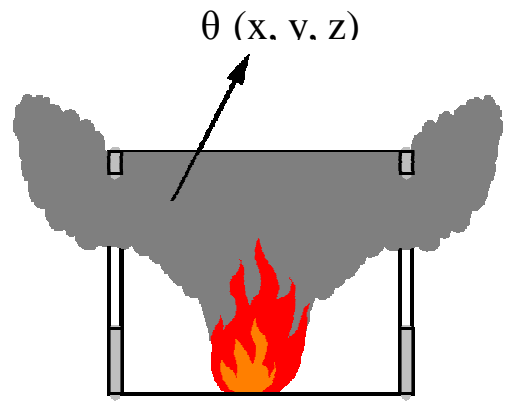

Localized fire in the compartment

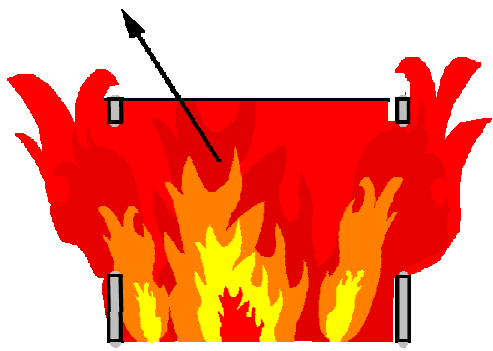

Fully engulfed fire

Fig. (3): Localized and fully engulfed fire

Mainly, the three levels of modeling are simplified, zone and filed models, as shown in Table (1).

Table (1): Different levels of fire models

\begin{tabular}{||l|c|c||}
\hline \hline LEVELS OF THE MODEL & LOCALIZED & GENERALIZED FIRE \\
\hline Simplified & $\begin{array}{c}\text { Hasemi model } \\
\text { Heskestad model }\end{array}$ & Parametrical fires \\
\hline Zone models & 2-zone model & 1-zone model \\
\hline Filed model & CFD & CFD \\
\hline
\end{tabular}

The simplified models are generally empirical models. The zone-models take into account all the main parameters controlling the fire, but introduce simplified assumptions that limit the domain of application. The field models are rather complex for being used as a general design tool and should be limited to specific cases [19]. Field models are the only tools valid for a complex geometry. The last European 
Community of Steel and Coal research projects were focusing on the improvement or the development of empirical and numerical tools [20,21, and 22].

The fire model utilized for the analyses presented in this study is composed of a one-zone and a two-zone model as well as a model to switch from the two-zone to the one-zone model $[23,24]$. Zone models are numerical tools commonly used for the evaluation of the temperature development of the gases within a compartment during the course of fire. It has been developed in the scoop of the ECCS researches "Natural Fire Safety Concept" (NFSC1) [25] and "Natural Fire Safety Concept - Full Scale Tests, Implementation in the Eurocodes and Development of an User Friendly design tool" (NFSC2) [26]. Based on a limited number of hypotheses, they are easy to use and provide a good evaluation of the situation provided they are used within their real field of application. Since the first numerical one zone models have been made by Peterson, major development of the numerical fire modeling has been done. Among other things, multi zones, multi-compartment and computational field dynamics models have been developed

The main hypothesis in zone models is that the compartment is divided in zones in which the temperature distribution is uniform at any time.

Figure (4) shows a schematic view of the two-zone model and its sub-models for heat and mass transfer. In the two-zone model, the compartment is divided in an upper and a lower layer. In each layers the gas properties (temperature, density, etc.) are assumed to be uniform.

The pressure is assumed to be constant throughout the whole compartment volume, except when it is evaluated that mass exchanges through vents.

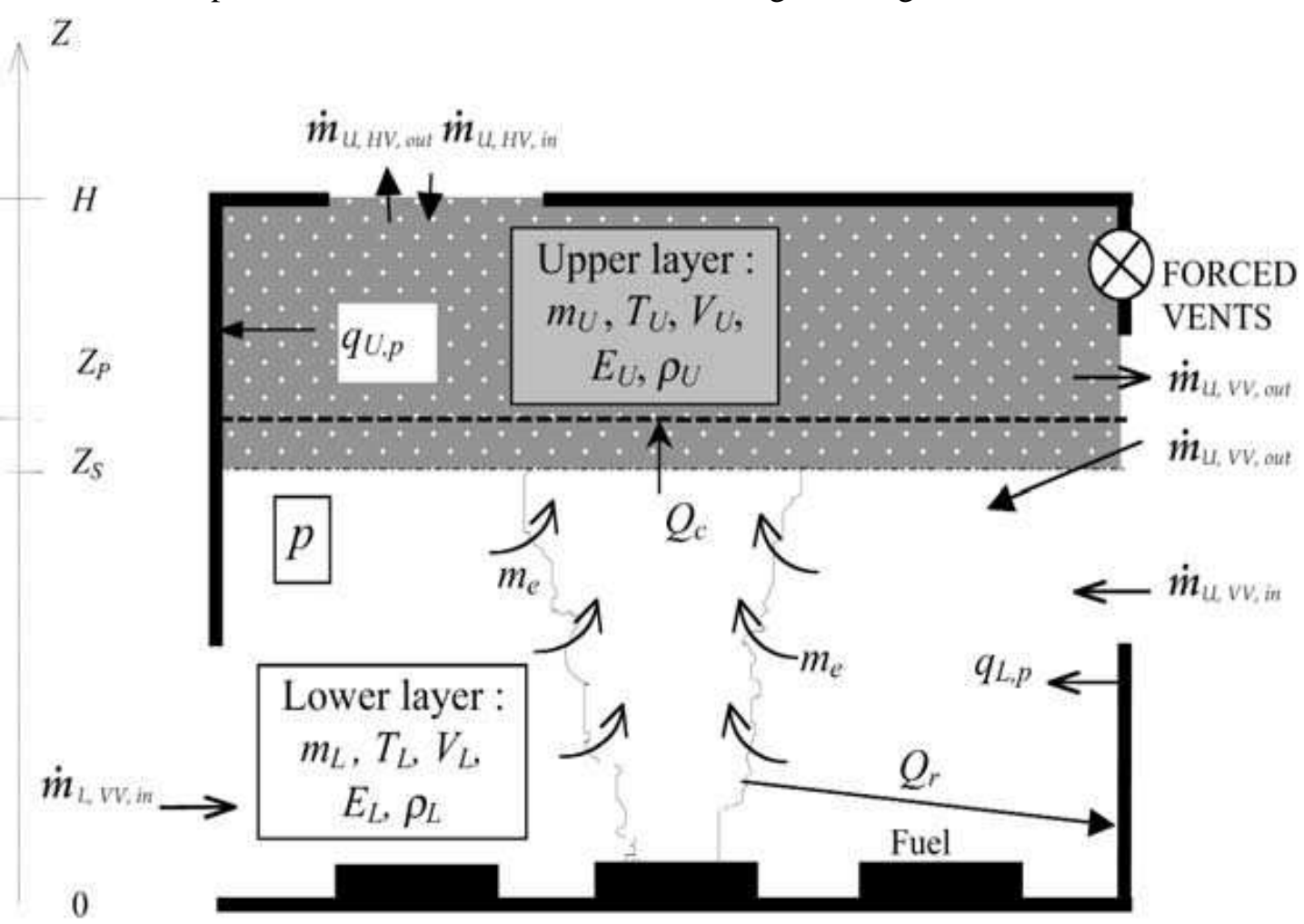

Fig. (4):Schematic view of two-zone model and associated sub-models 
Some switch criteria are defined so that they represent a limit beyond which one-zone model assumptions becomes closer to the physics of the fire situation than the two-zone model. The switch is made so that the total energy and mass present in the two-zone model system at time of switch are fully conserved in the one-zone model system.

Figure (5) shows a schematic view of the one-zone model and its sub models for heat and mass transfer. In the one-zone model, a single zone represents the compartment. In this zone the temperature and density are assumed to be uniform. The pressure is assumed to be constant on the whole compartment volume (except while evaluating mass exchange through vents). The zone is supposed to be opaque. Radiative and convective heat transfers connect partitions to it. Validation of OZONE model can be found in [23].

Z

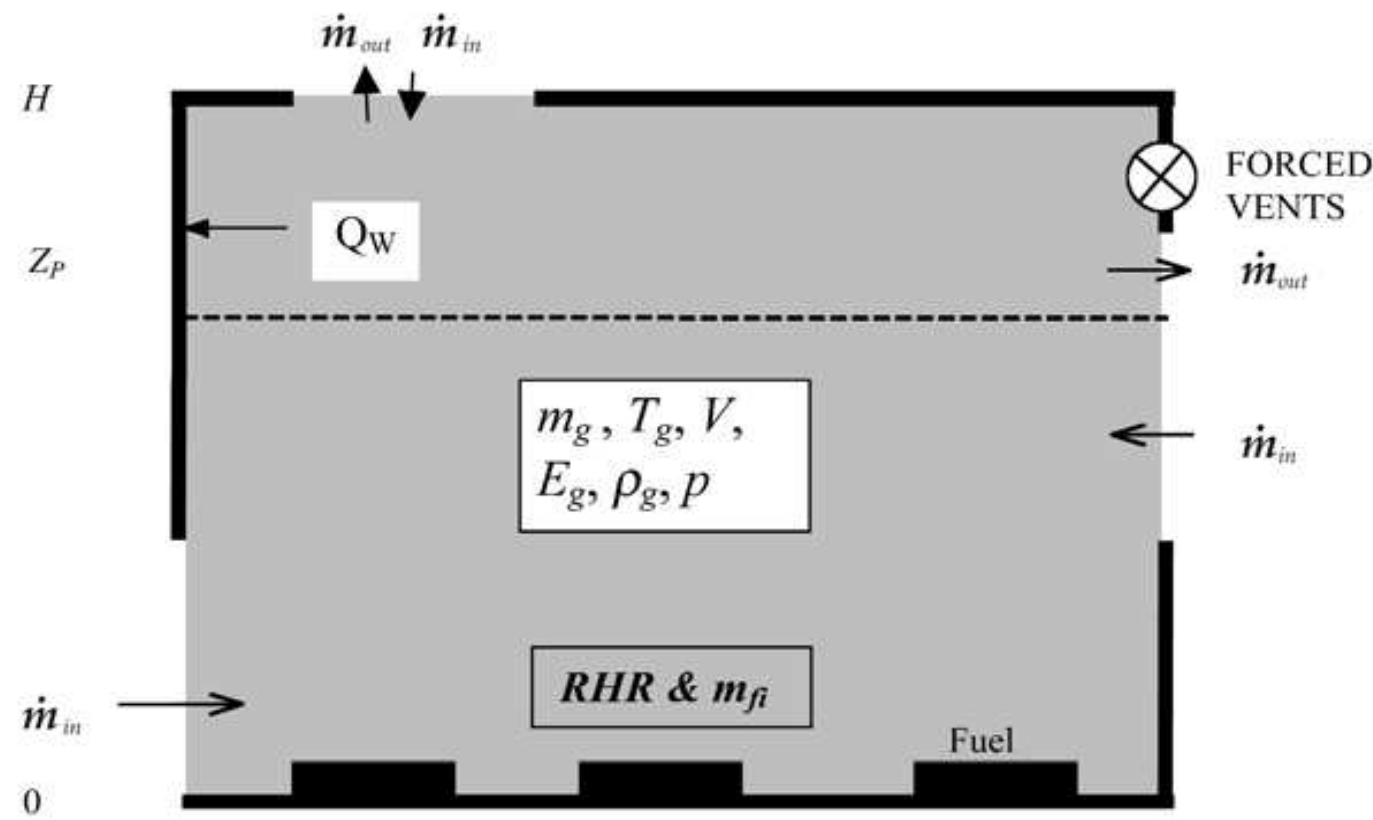

Fig. (5): Schematic view of one-zone model and associated sub-models

\subsection{Rate of Heat Release}

To simulate a fire in a building and its effect on the structure of this building, the rate of heat release (RHR) given in $\mathrm{kW}$ as function of time must be defined. At the beginning, the fire starts small and produces little heat. It then grows and begins to spread. The fire-spread velocity depends on the type of building and its use. The buildings are classified into four categories according to the fire-spread velocity: low, medium, fast and ultra-fast (see Table (2))[23]. The fire power increases up to a maximum which corresponds to the RHR maximum per $\mathrm{m}^{2}$ which depends on the building type, multiplied by the fire area. This surface is the whole compartment area $\left(A_{f}\right)$ or, in some cases, it is only the surface where the fire load is localized $\left(A_{f i}\right)$. 
However, generally, the fire does not remain localized. For instance, in a library building, the fire spreads and finally engulfs the whole compartment.

Table (2): Fire Growth Rate, Fire Loads and $\mathrm{RHR}_{\mathrm{f}}$ for different buildings

\begin{tabular}{||c|c|c|c||}
\hline OCCUPANCY & $\begin{array}{c}\text { FIRE GROWTH } \\
\text { RATE }\end{array}$ & $\begin{array}{c}\text { RHR } \\
\left(\mathrm{KW}_{\mathrm{F}}{ }^{2}\right.\end{array}$ & $\begin{array}{c}\text { FIRE LOAD } \\
q_{f, k}\end{array}$ \\
\hline Dwelling & Medium & 250 & 984 \\
\hline Hospital(room) & Medium & 250 & 280 \\
\hline Hotel(room) & Medium & 250 & 377 \\
\hline Library & Fast & 500 & 1824 \\
\hline Office & Medium & 250 & 511 \\
\hline School & Medium & 250 & 347 \\
\hline Shopping Centre & Fast & 500 & 730 \\
\hline Theatre & Fast & 500 & 365 \\
\hline Transport (public space & Slow & 250 & 122 \\
\hline
\end{tabular}

At the end of the growing phase, after that the whole compartment has been involved in the fire, the fire reaches a stationary state corresponding to the horizontal plateau of the RHR curve. The value of this plateau can be equal to the area of the compartment multiplied by the $\mathrm{RHR}_{\mathrm{f}}$ corresponding to a fuel controlled fire or the value of this plateau is fixed by the oxygen content in the compartment. In this last case the fire is called ventilation controlled. Following this steady rate of burning, when about $70 \%$ of the fuel has been consumed, the fire begins to decline.

The fire load defines the available energy but the gas temperature in a fire is more dependent on the rate of heat release. The same fire load burning very quickly or smoldering can lead to completely different gas temperature curves.

The RHR is the source of the gas temperature rise, and the driving force behind the spreading of gas and smoke. A typical fire starts small and goes through a growth phase. Two things can then happen depending whether during the growth process there is always enough oxygen to sustain combustion. Either, when the fire size reaches the maximum value without limitation of oxygen, the RHR is limited by the available fire load (fuel controlled fire). Or, if the size of openings in the compartment enclosure is too small to allow enough air to enter the compartment, the available oxygen limits the RHR and the fire is said to be ventilation controlled. Both ventilation and fuel-controlled fires can go through flashover.

\subsection{Fire Load Density - $q_{f}$}

The characteristic fire load density $q_{f, k}$ considered in the NFSC Design Fire is the $80 \%$ fractile of the fire load distribution obtained by survey in real compartments. Data are available for different types of occupancies of compartments. In order to obtain these data's, the mass of combustible present in compartments has been measured and then multiplied by the combustion heat of the fuel and divided by the floor area of the compartment. The complete combustion heat has been considered in these evaluations [24]. 
$q_{f, k}=H_{C, n e t} \frac{m_{f i}}{A_{f}}$

Where $H_{C, \text { net }}, m_{f i}$ and $A_{f}$ are the complete combustion heat of fuel, the total mass of fuel and the floor area of the compartment respectively.

The design fire load density is given by:

$q_{f, d}=\gamma_{q 1} \cdot \gamma_{q 2} \cdot \prod_{i} \cdot \gamma_{n, i} \cdot m \cdot q_{f, k}$

Where

$\gamma_{q 1}$ is a factor taking into consideration the compartment area

$\gamma_{q 2}$ is a factor taking into consideration the danger of fire activation

$\gamma_{n, i}$ are factors depending on the active fire resistance methods

$m$ is the combustion efficiency factor (usually $80 \%=0.8$ )

$q_{f, k}$ is the characteristic fire load density

The value of $\gamma_{q 1}$ can be calculated as follows:

$\gamma_{q 1}=0.1688 \operatorname{Ln}\left(A_{f}\right)+0.5752$

The influence of the danger of fire activation $\gamma_{q 2}$ and active measures are given in Table (3) and (4) respectively.

Table (3): Values of danger of fire activation factor

\begin{tabular}{||l|c|}
\hline \hline DANGER OF FIRE ACTIVATION & $\gamma_{q 2}$ \\
\hline low & 0.85 \\
\hline Medium & 1.0 \\
\hline High & 1.2 \\
\hline Very high & 1.4 \\
\hline Ultra high & 1.6 \\
\hline
\end{tabular}

Table (4): Values of active measures factor

\begin{tabular}{||l|l|l||}
\hline CASE & ACTIVE MEASURES & $\gamma_{n, i}$ \\
\hline 1 & Automatic Water Extinguishing System & 0.61 \\
\hline $1-\mathrm{a}$ & Independent Water Supplies 1 & 0.87 \\
\hline $1-\mathrm{b}$ & Independent Water Supplies 2 & 0.7 \\
\hline 2 & Automatic Fire Detection by Heat & 0.87 \\
\hline 3 & Automatic Fire Detection by Smoke & 0.73 \\
\hline 4 & $\begin{array}{l}\text { Automatic Alarm Transmission to Fire } \\
\text { Brigade }\end{array}$ & 0.87 \\
\hline 5 & Work Fire Brigade & 0.61 \\
\hline 6 & Off Site Fire Brigade & 0.78 \\
\hline
\end{tabular}




\section{AIR TEMPERATURE}

From the fire model, based on various input parameters, the temperatures in the compartment are predicted. The heat loss by convection, radiation and conduction from the compartment is an important factor for the temperature determination. Through the separating element, according to the thermal inertia of the wall (insulated or not), this heat loss is within the range of $30 \%$ to $90 \%$ of the total amount of heat released within the compartment by the combustion of fire load, and consequently the thermal properties of the walls have to be known [7].

\section{CASE OF STUDY}

To study the influence of each parameter individually, the building, as shown in Fig. (6), was taken as a case of study. The building is compartmented by fire walls composed of normal bricks with a thickness of $25 \mathrm{~cm}$. The geometry of the studied compartment is; $8 \mathrm{~m}$ width, $12 \mathrm{~m}$ depth and $4 \mathrm{~m}$ height, as shown in the figure. On wall 1 , there is a door opening with a height of $2.2 \mathrm{~m}$ and width of $1.5 \mathrm{~m}$. On wall 2 and wall 4, there are 4 windows with a width of $1.2 \mathrm{~m}$, a sill height of $1.0 \mathrm{~m}$ and a soffit height of $2.2 \mathrm{~m}$. The floor is a normal weight concrete slab with a thickness of $15 \mathrm{~cm}$. The ceiling consists of steel beams and composite slab with concrete and steel sheeting has a total thickness of $150 \mathrm{~mm}$. The type of building is a library. The fire area $A_{f i}$ was taken to be $24 \mathrm{~m}^{2}\left(0.25\right.$ of the total floor area $\left.A_{f}\right)$. Off site fire brigade is selected as an active measure, Case 6 in Table (4). The results of the input data are shown in Figs. (7) to (11).

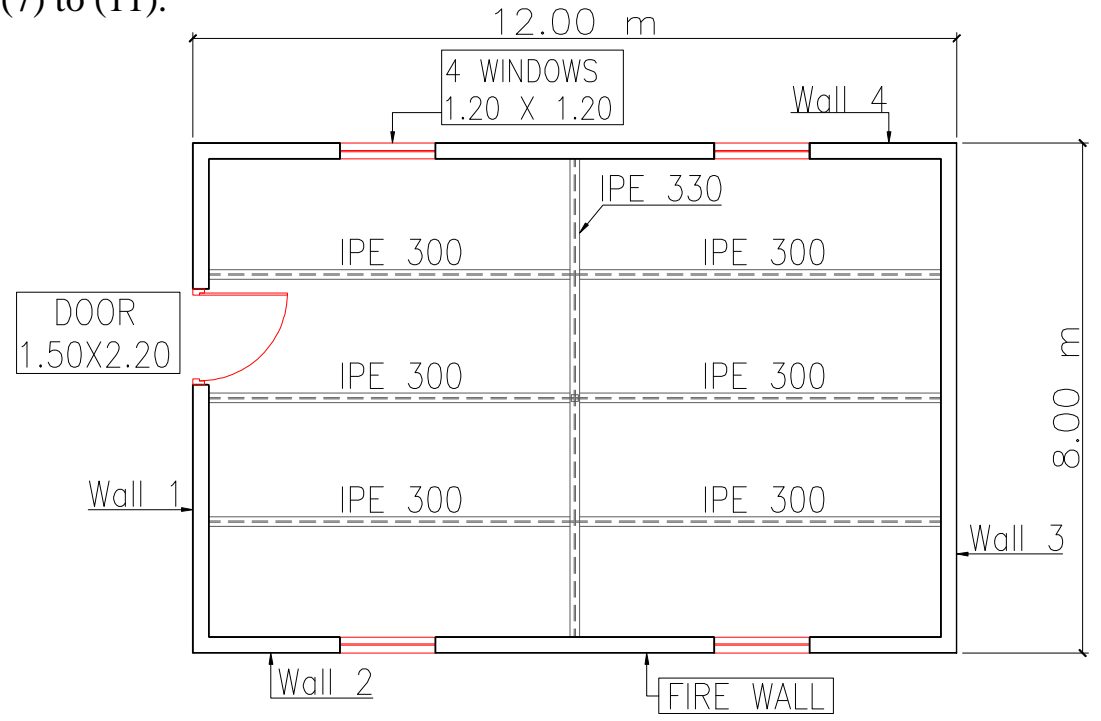

Fig. (6): Geometry of the fire compartment

Figure (7) shows the rate of heat release data and computed. RHR data results are based directly on the input data, whilst RHR computed are results modified by the amount of oxygen available to the fire during calculation. 


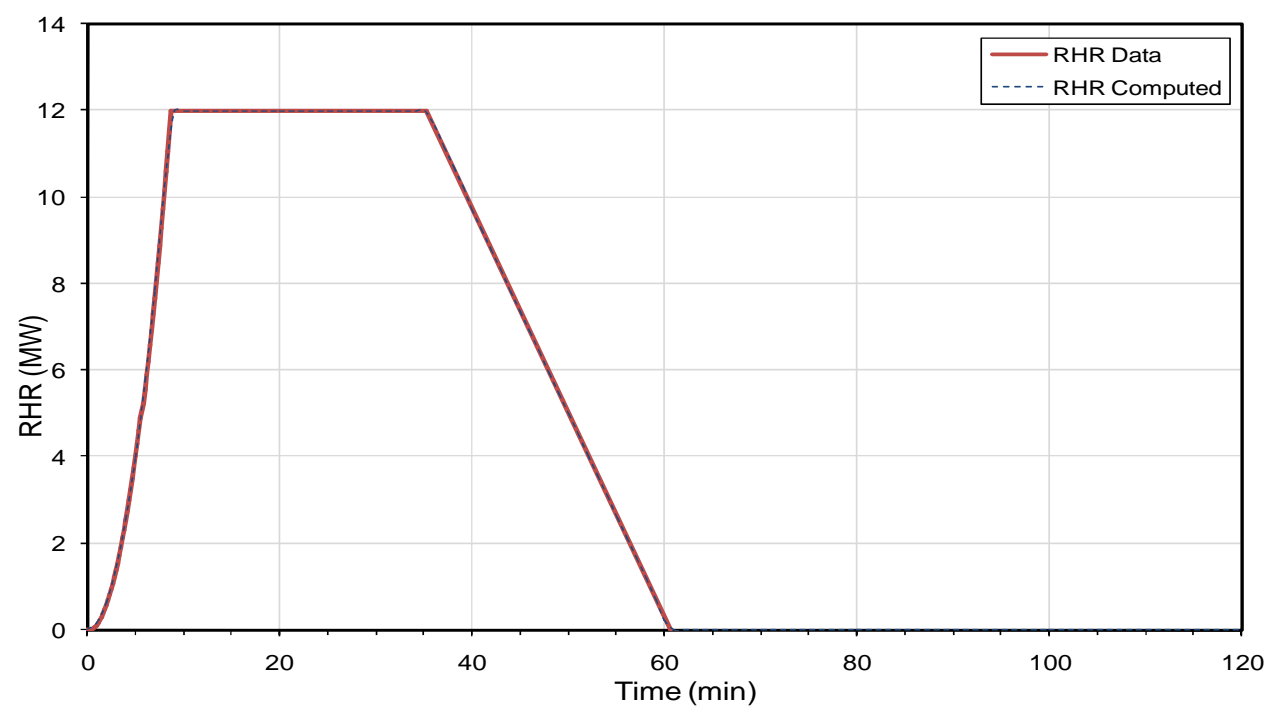

Fig. (7): RHR Data and Computed

If the fire is limited by the amount of oxygen, the computed graphs will run lower than the original data graphs. On the other hand, if the fire is limited by the amount of fuel (with oxygen not being a limiting factor), the computed graphs will most likely experience flashover and there will be a sudden rise in the graphs as in our case.

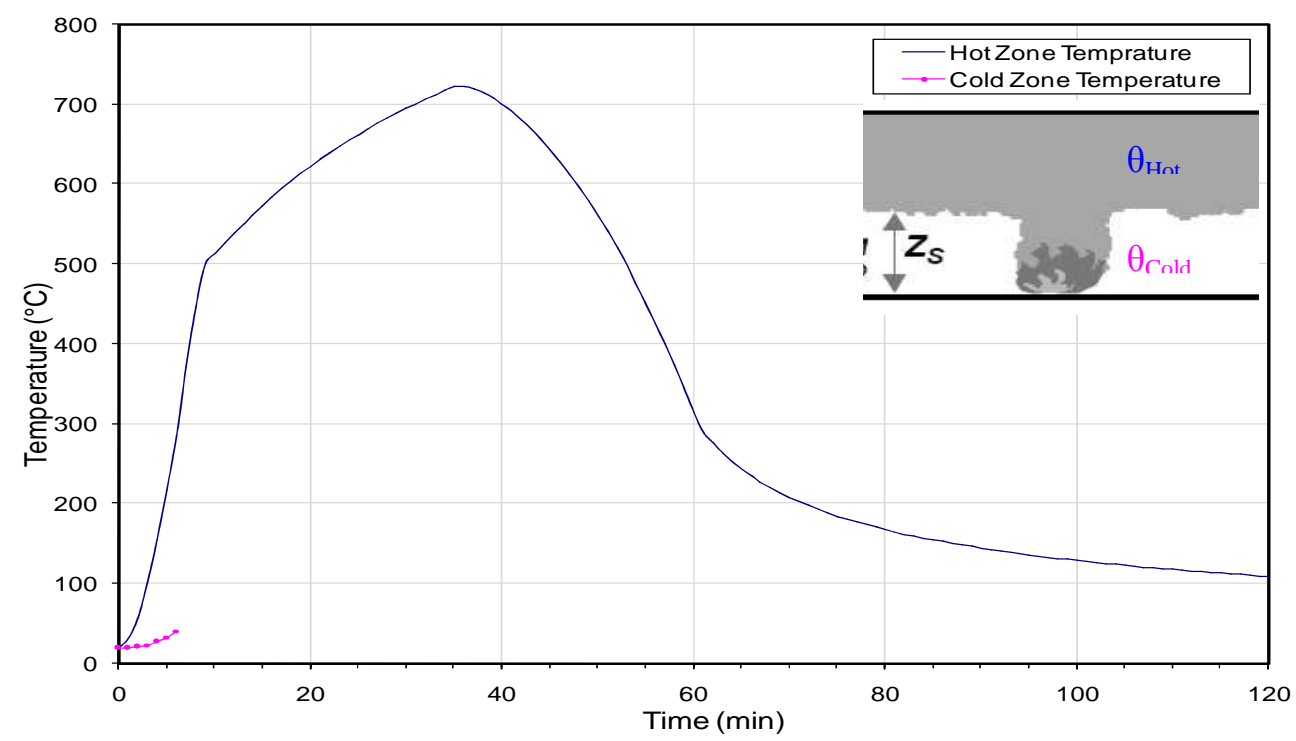

Fig. (8): Hot and Cold Zone Temperature

As the fire starts, the process begins with the creation of two zones, hot and cold zones as shown in Fig. (8). As the time proceeds, the height of the cold zone $Z_{S}$ decreases till it reaches a certain value, the process switches from the two-zone case to a one-zone case and modifications happens to the mass and energy released by the fire. 
This phenomenon is clearly shown by Fig. (9), that after a time of 6 minutes, the cold zone height $Z_{S}$ reached a value of $0.84 \mathrm{~m}$. this means that a one-zone case becomes more realistic when the upper layer thickness becomes large compared to the compartment height.

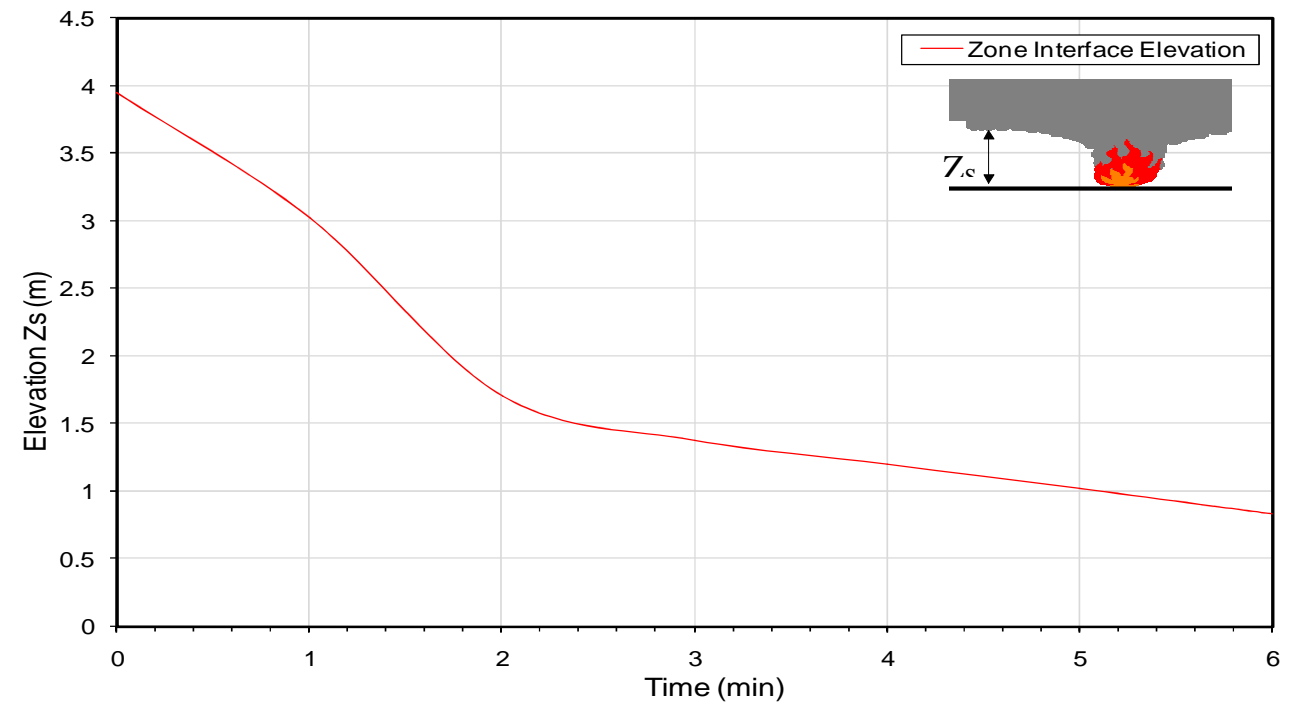

Fig. (9): Zones Interface Elevation

The fire area is the burning area of fuel. In real fires, it is usually varying with time. This is clearly demonstrated by Fig. (10). At a time of 9 minutes, the fire area reached its peak value of $24 \mathrm{~m}^{2}$. During the period between 9 minutes up to 35 minutes, the fire area became constant. After a time of 35 minutes, it decays to become zero at a time of 60 minutes.

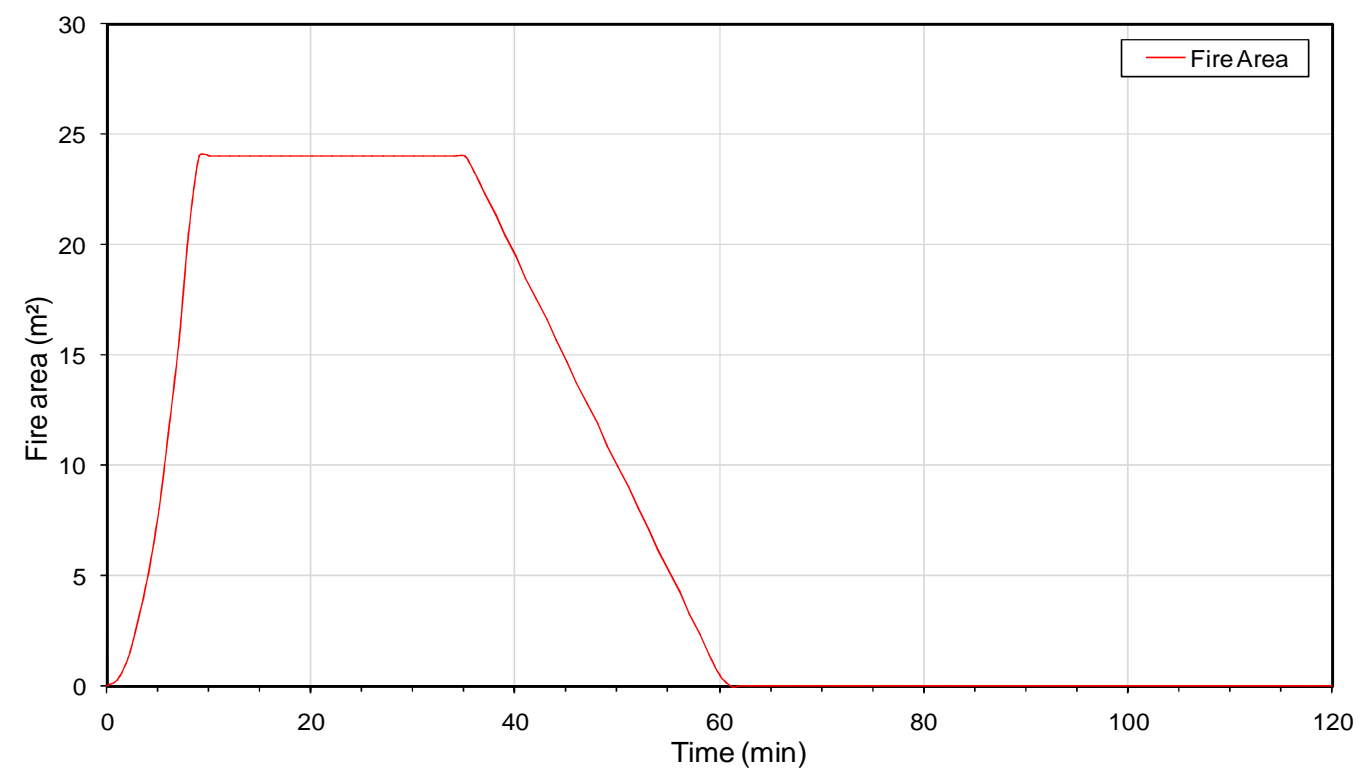

Fig. (10): Fire Area 
Compared to the floor area of the compartment $A_{f}$, the fire area $A_{f i}$ is too high to be considered as a localized fire, that it is $25 \%$ of the former. This is another reason for a fire scenario to be switched from two-zone to one-zone case.

Figure (11) shows the temperature development in the steel beam due to the gas or hot zone temperature. In the growth phase, it clear that the temperature in the unprotected steel section tends to follow the evolution of the gas temperature with a rather limited delay. The maximum steel temperature is therefore sensitive to the severity of the fire, much more than to the duration of the fire.

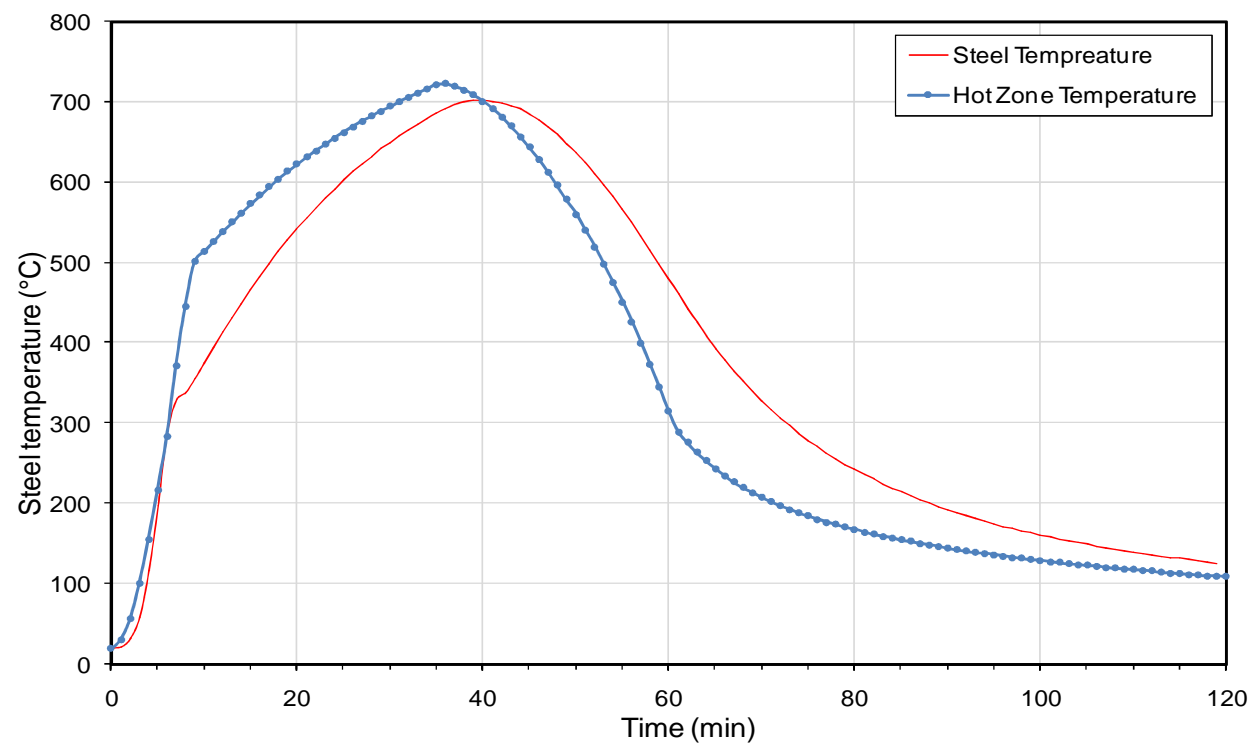

Fig. (11): Hot zone and steel temperatures

\section{INFLUENCE OF DIFFERENT PARAMETERS ON THE STEEL BEAM TEMPERATURE}

In this section, the investigated compartment in section 4 was taken as a reference, and the influence of the important parameters on fire scenario and consequently on the steel beams temperature inside the compartment have been studied individually. These important parameters include fire area $A_{f i}$, active measures, ventilations, compartment height $H$, compartment floor area $A_{f}$, compartment rectangularity, wall type, wall thickness, protection shape, protection thickness and protection type.

\subsection{Influence of Fire Area}

The effect of different values of fire or fuel area on the steel member temperature is shown in Fig. (12). The values of fire area used in this study are $24 \mathrm{~m}^{2}, 48 \mathrm{~m}^{2}, 72 \mathrm{~m}^{2}$ and $96 \mathrm{~m}^{2}$ which represent ratios $25 \%, 50 \%, 75 \%$ and $100 \%$ from the floor area. It is clear from the figure that as the fire area increases, the steel temperature increases and the curve which represents the relation between time and steel temperature become more open. For small values of fire area, the relation between time and steel temperature takes growth and decay phases while for higher values, the relation only takes a grow phase. 


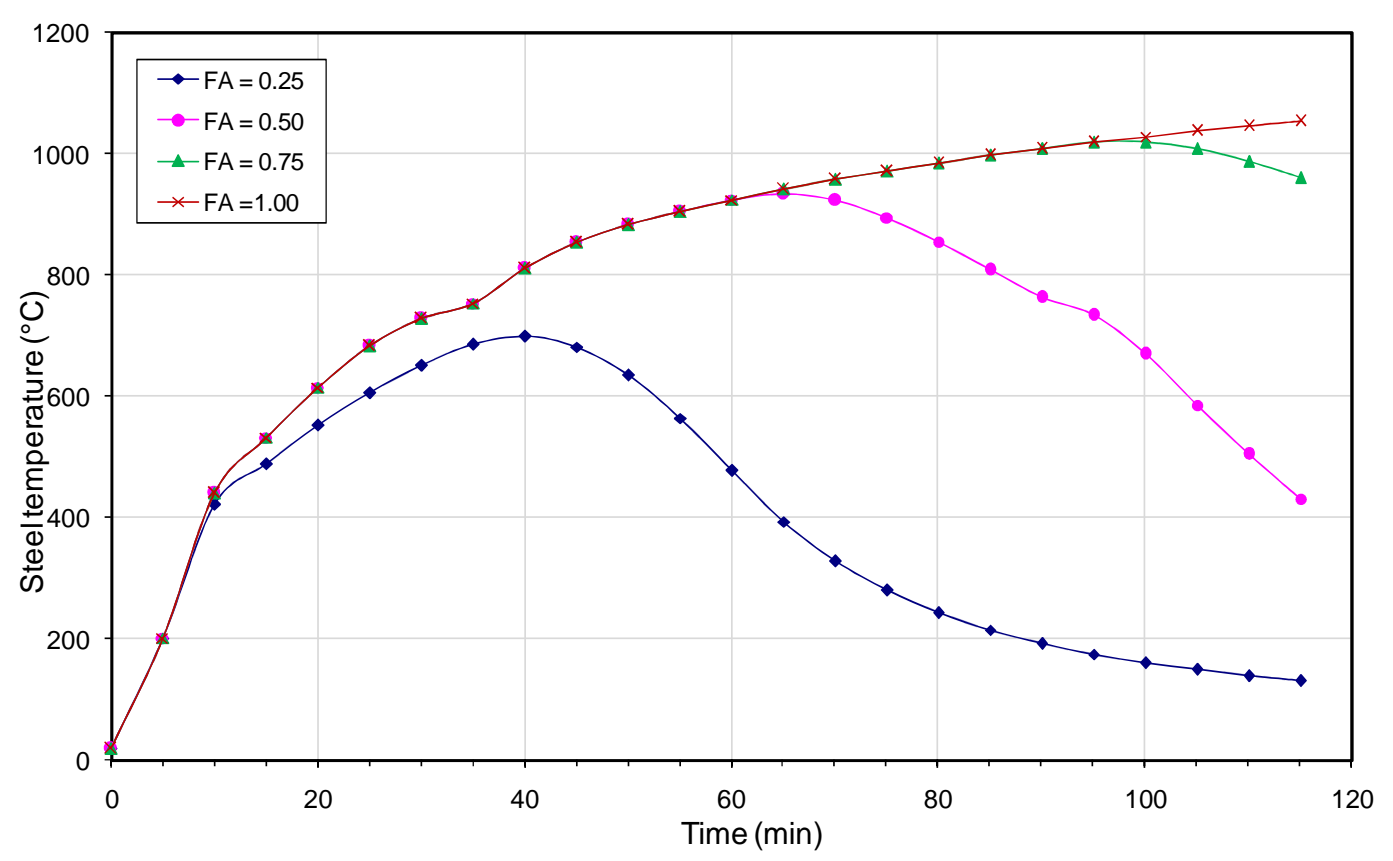

Fig. (12): Influence of fire area on steel beam temperatures

\subsection{Influence of active Measures}

Active fire protection systems such as water sprinkler and spray systems are widely used in the process industries for protection of storage vessels, process plant, loading installations and warehouses. The duty of the fire protection system may be to extinguish the fire, control the fire, or provide exposure protection to prevent domino effects. Figure (13) shows the influence of using active measure on the steel temperature. When no active measure is used, the result shows that the fire is always in developing stage and the maximum temperature was achieved at the end of the studying period (120 $\mathrm{min}$ ). When the Off Site fire brigade was used (case 6 in Table 3), the curve which represents the change of steel temperature with time turned to be closed and growth and decay phases appeared. The peak temperature is reduced from $935{ }^{\circ} \mathrm{C}$ in case of no active measures to $700{ }^{\circ} \mathrm{C}$ in case using off site fire brigade. When using cases $(6+4)$, cases $(6+4+3)$ and cases $(6+4+3+1)$ in Table (3), the relation became more close and the peak temperature reduced to be $673^{\circ} \mathrm{C}, 616^{\circ} \mathrm{C}$ and $573{ }^{\circ} \mathrm{C}$ respectively.

\subsection{Influence of Ventilation}

Three types of vent models have been introduced in Ozone program: vertical vents; horizontal vents and forced (mechanical) vents. During the course of a fire, the number of vents which are opened can vary. Their size can also be modified. This can be the result of glazing breakage, automatic opening or firemen arrival... In OZone, the opened vent size can be defined to be a function of the temperature of the zone in contact with the glass $(T Z)$ or to be a function of time. Criteria function of zone temperature can represent breakage due to thermal action. Criteria function of time can represent the firemen arrival. 


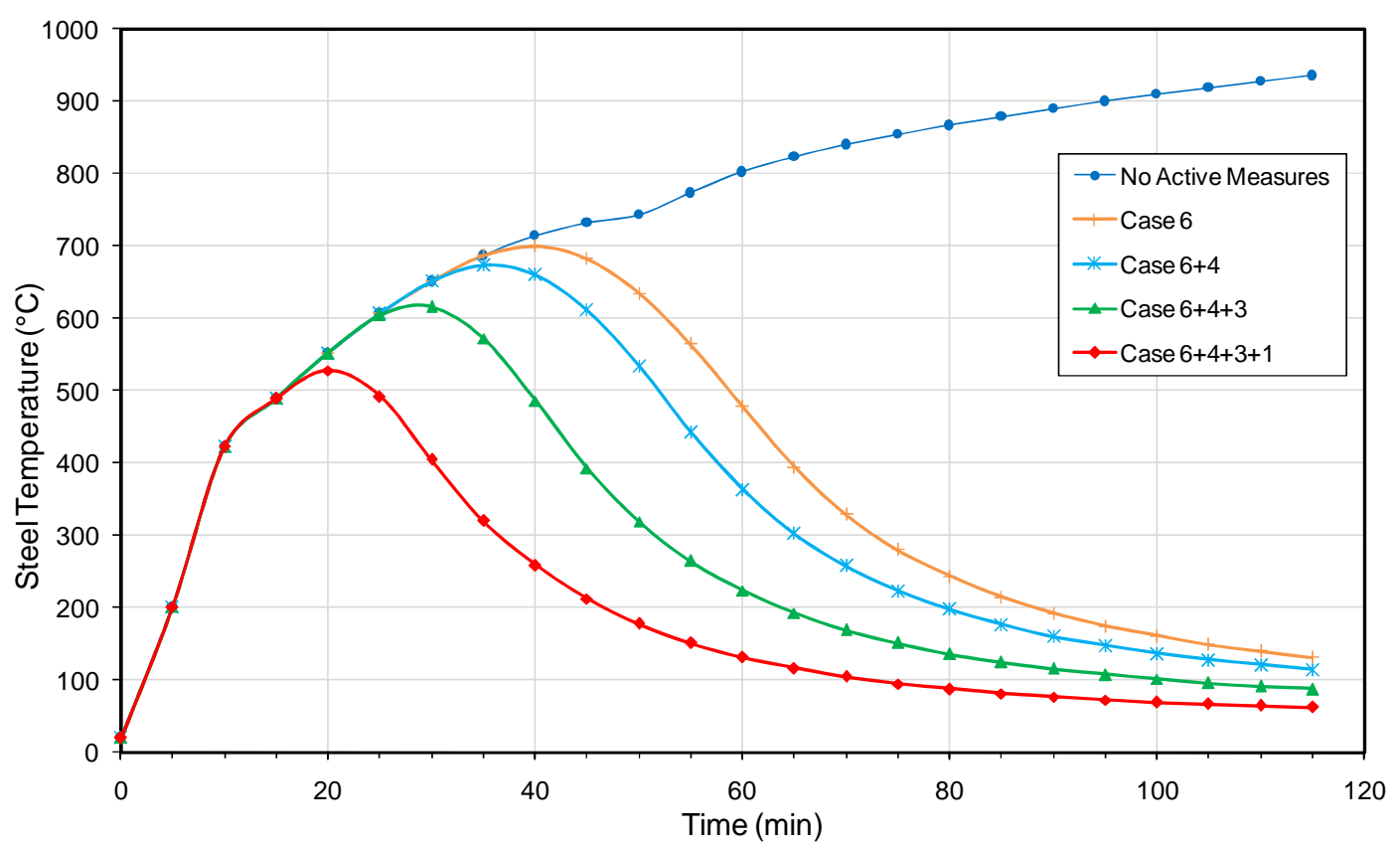

Fig. (13): Influence of active measures on steel temperatures

Figure (14) shows the effect of opening factor on steel temperature. According to BS code, the opening factor "O" can be calculated as follows:

$O=\frac{A_{v} \sqrt{h_{e q}}}{A_{t}}$

Where $A_{v}, A_{v}$ and $A_{v}$ are the total area of openings in walls, the average height of windows and the total area of enclosures (walls, ceiling, opening and floor) respectively.

Comparing tests of low versus high opening factors, there is a delay in the growth rate for the higher opening factor cases. The peak values are also lower.

\subsection{Influence of Compartment Height}

Figure (15) shows the influence of compartment height " $\mathrm{H}$ "on the steel beam temperature. It is clear from the figure that as the height increases, the rate of fire growth as well as the peak temperature decreases. Also, the results show that compartment height does not affect the time at which the peak temperature attained. The peak temperature decreases from $724{ }^{\circ} \mathrm{C}$ for $\mathrm{H}$ equal to 3.0 meter to $598{ }^{\circ} \mathrm{C}$ for $\mathrm{H}$ equal to 8.0 meter. 


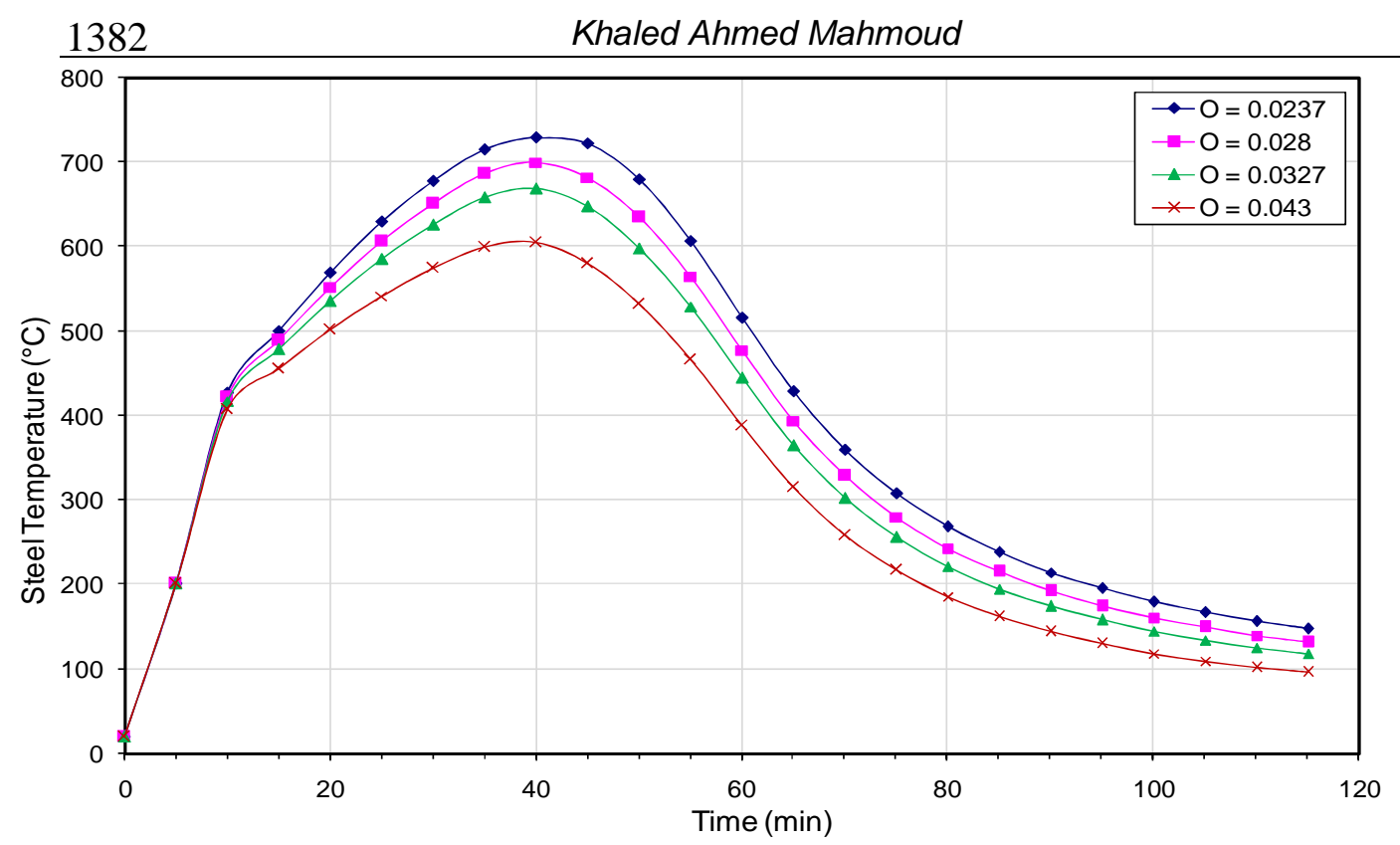

Fig. (14): Influence of active measures on steel temperatures

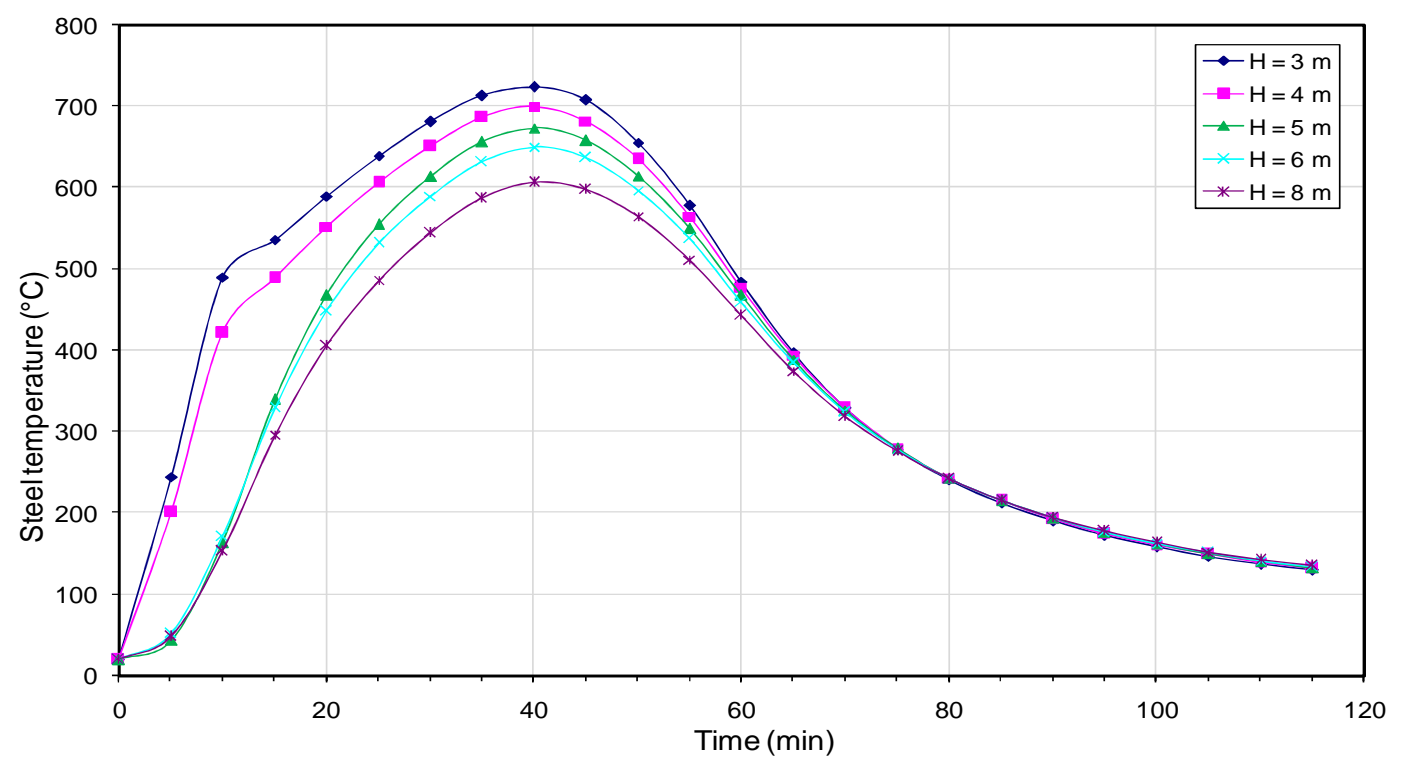

Fig. (15): Influence of compartment height on steel beam temperatures

\subsection{Influence of Compartment Floor Area}

If large floor area is used, a large fuel area attained and consequently a big amount of heat flux releases. This result is clearly demonstrated by Fig. (16). By comparing results of different floor area dimensions, it can be seen that there is an increase in the growth rate, with peak temperatures attained 10-30 minutes later, for the higher dimension cases. The peak values are also higher that they were $296{ }^{\circ} \mathrm{C}, 682{ }^{\circ} \mathrm{C}, 774$ ${ }^{\circ} \mathrm{C}$ and $800{ }^{\circ} \mathrm{C}$ for $24 \mathrm{~m}^{2}, 96 \mathrm{~m}^{2}, 192 \mathrm{~m}^{2}$ and $384 \mathrm{~m}^{2}$. 


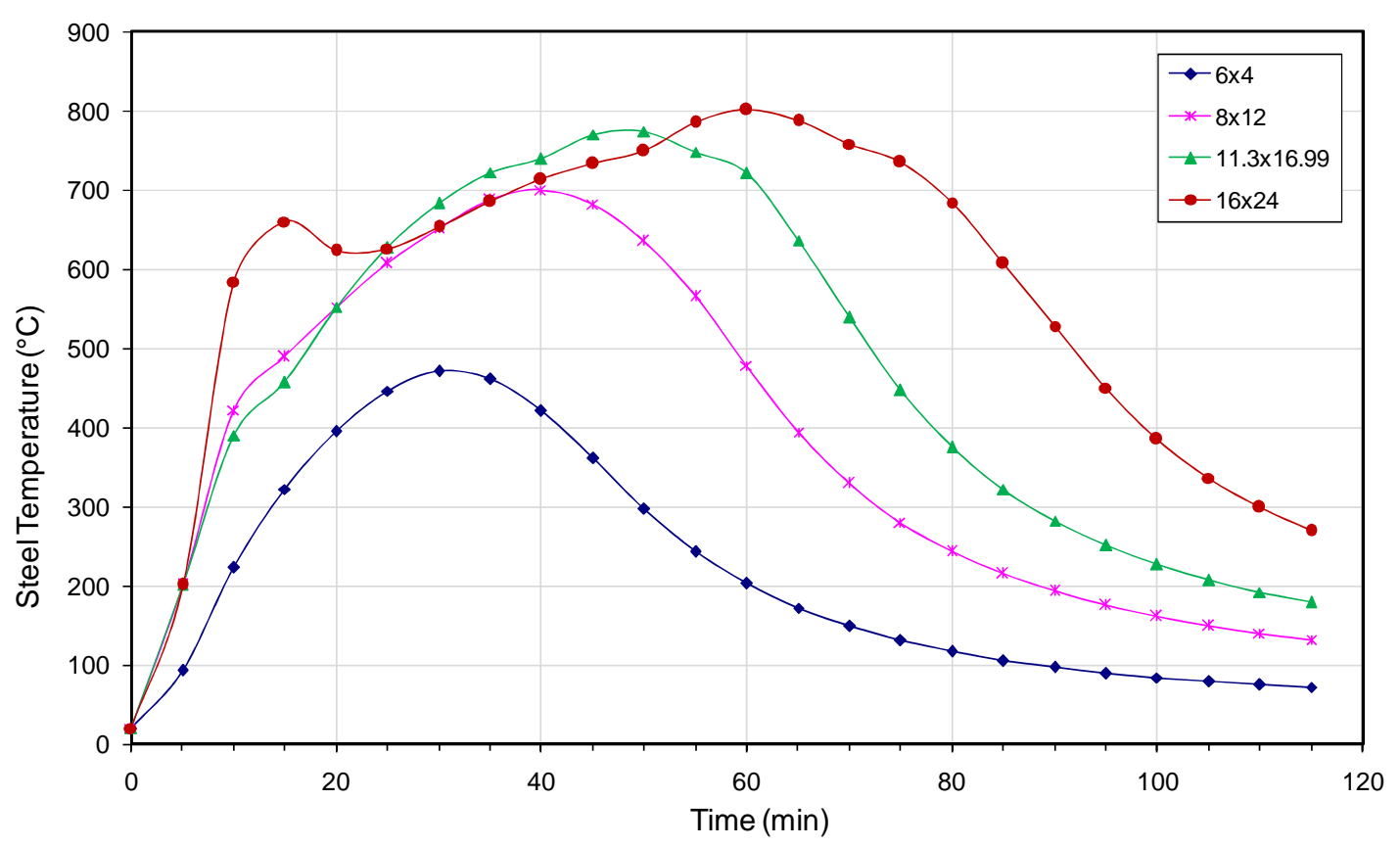

Fig. (16): Influence of compartment floor area on steel beam temperatures

\subsection{Influence of Compartment Rectangularity}

The influence of rectangularity $(\mathrm{L} / \mathrm{b})$ of floor area on the temperature development of the steel beams is shown in Fig. (17). While the floor area was kept to be constant, four values of rectangularity $\mathrm{L} / \mathrm{b} 1.0,1.5,2.67$ and 4 which represent a floor area of $9.8 \times 9.8$, $8 \times 12,6 \times 16$ and $4 \times 24 \mathrm{~m}^{2}$ respectively were taken into consideration. Comparing the results where compartment rectangularity was varied reveals a minor influence overall, with small differences. The results were identical in case of $\mathrm{L} / \mathrm{b}=1.0$ and 1.5 while the peak temperature start to decrease for higher values of $\mathrm{L} / \mathrm{b}$.

\subsection{Influence of Wall type and Wall Thickness}

It has long been recognized that the combination of the thermal properties $\mathrm{k}, \rho$ and $\mathrm{c}$ where, $\mathrm{k}$ is the thermal conductivity, $\rho$ is the density and $\mathrm{c}$ the thermal capacity, of a material has an important role to play in the time constant of heating materials and the growth of fires. Figure (18) illustrates the influence of steel temperature by different wall lining materials. In this study, concrete has the highest $k \rho c$ values while normal wood has the lowest values. For high values of $k \rho c$ where the compartment boundaries have been treated as a semi-infinite slab, $k \rho c$ delay the growth rate and reduce the peak temperature. This is because heat transfer through boundary notably becomes dependent on conductive flow process. The amount of heat transfer through the boundary depends also on the boundary thickness. This is illustrated in Fig. (19) that when the thickness increased from $12 \mathrm{~cm}$ to $25 \mathrm{~cm}$, the peak temperature reduced from $740{ }^{\circ} \mathrm{C}$ to $700{ }^{\circ} \mathrm{C}$. 


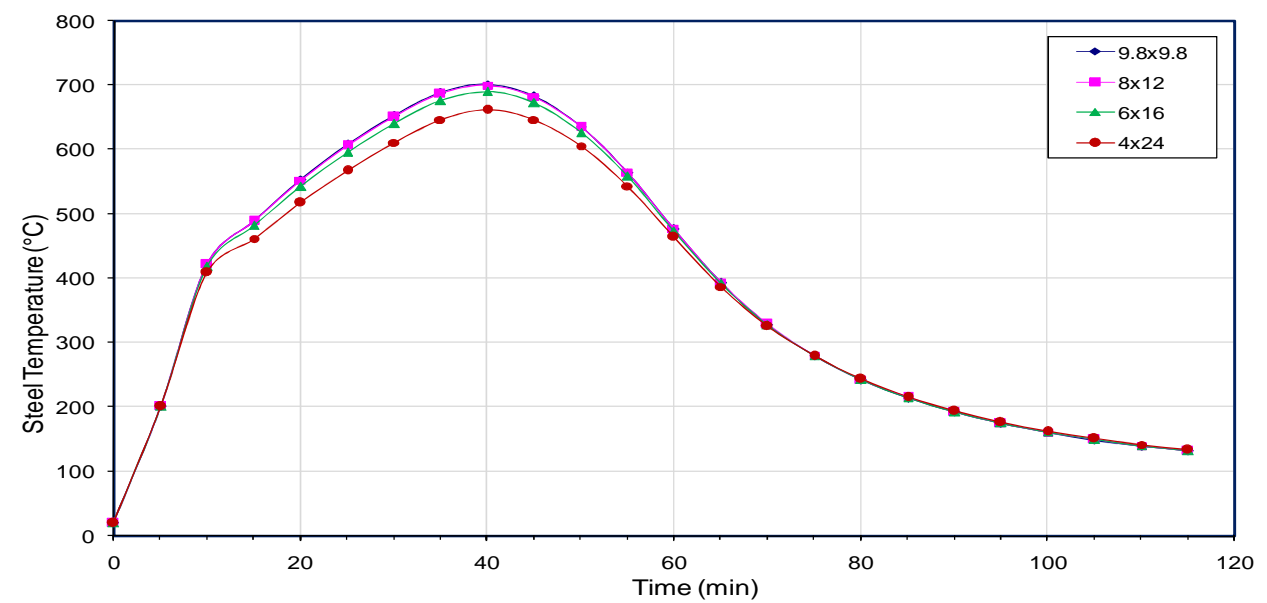

Fig. (17): Influence of compartment rectangularity on steel beam

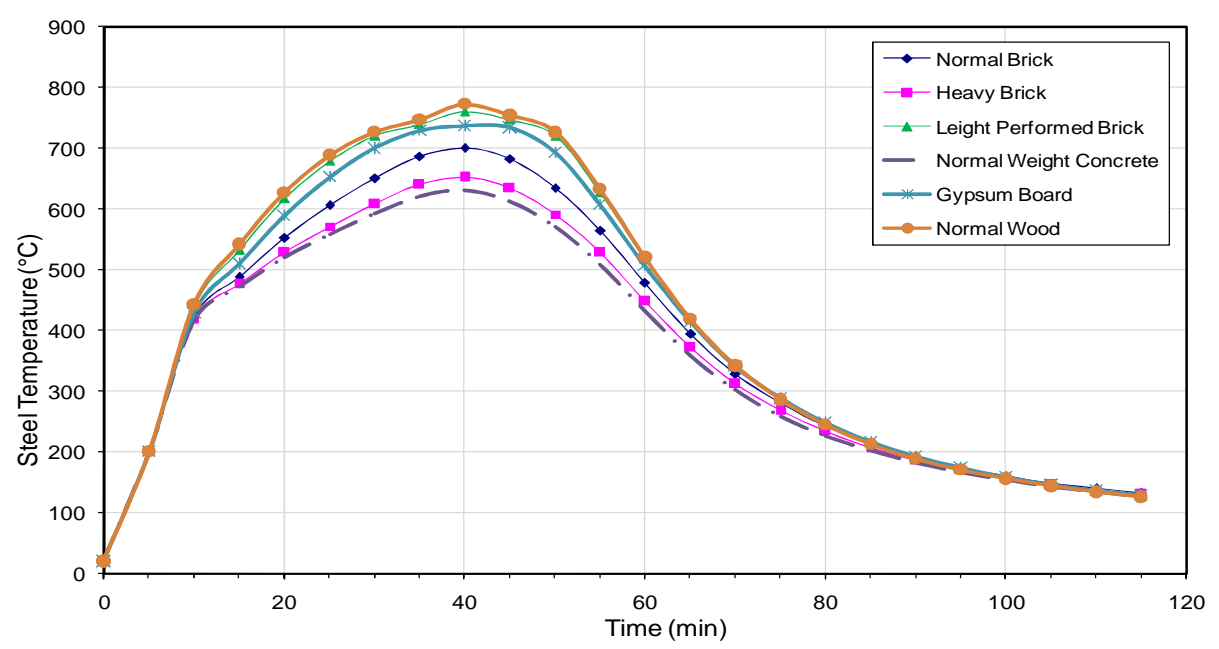

Fig. (18): Influence of wall type on steel beam temperatures

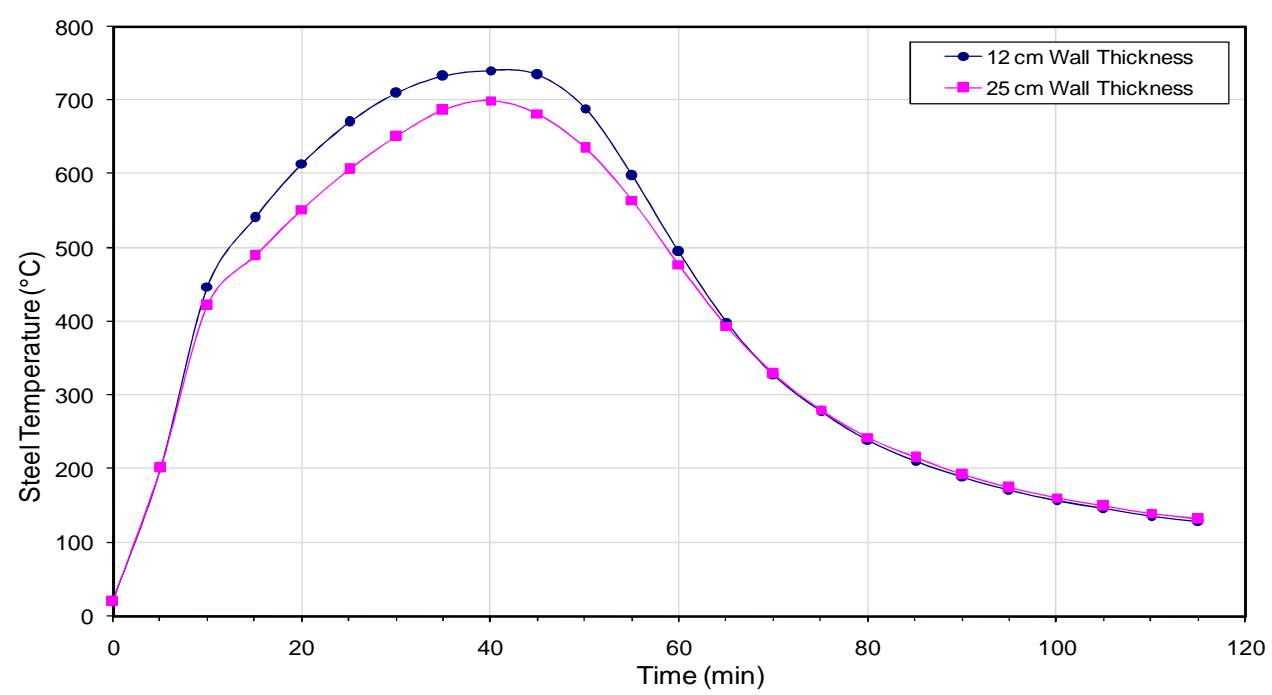

Fig. (19): Influence of wall thickness on steel beam 


\subsection{Influence of Protection Shape}

Figure (20) shows the temperature development for the unprotected and protected section. The protected section has two cases, contour encasement $C E$ and hollow encasement $H E$ protection. Both cases has $10 \mathrm{~mm}$ spray mineral fiber protection.

From Fig. (20), it can be seen that lower temperature are expected in the steel profile when using protection. The maximum temperature decrease from $700{ }^{\circ} \mathrm{C}$ where the section is unprotected to $466{ }^{\circ} \mathrm{C}$ and $414{ }^{\circ} \mathrm{C}$ where in case contour or hollow encasement protection is used respectively.

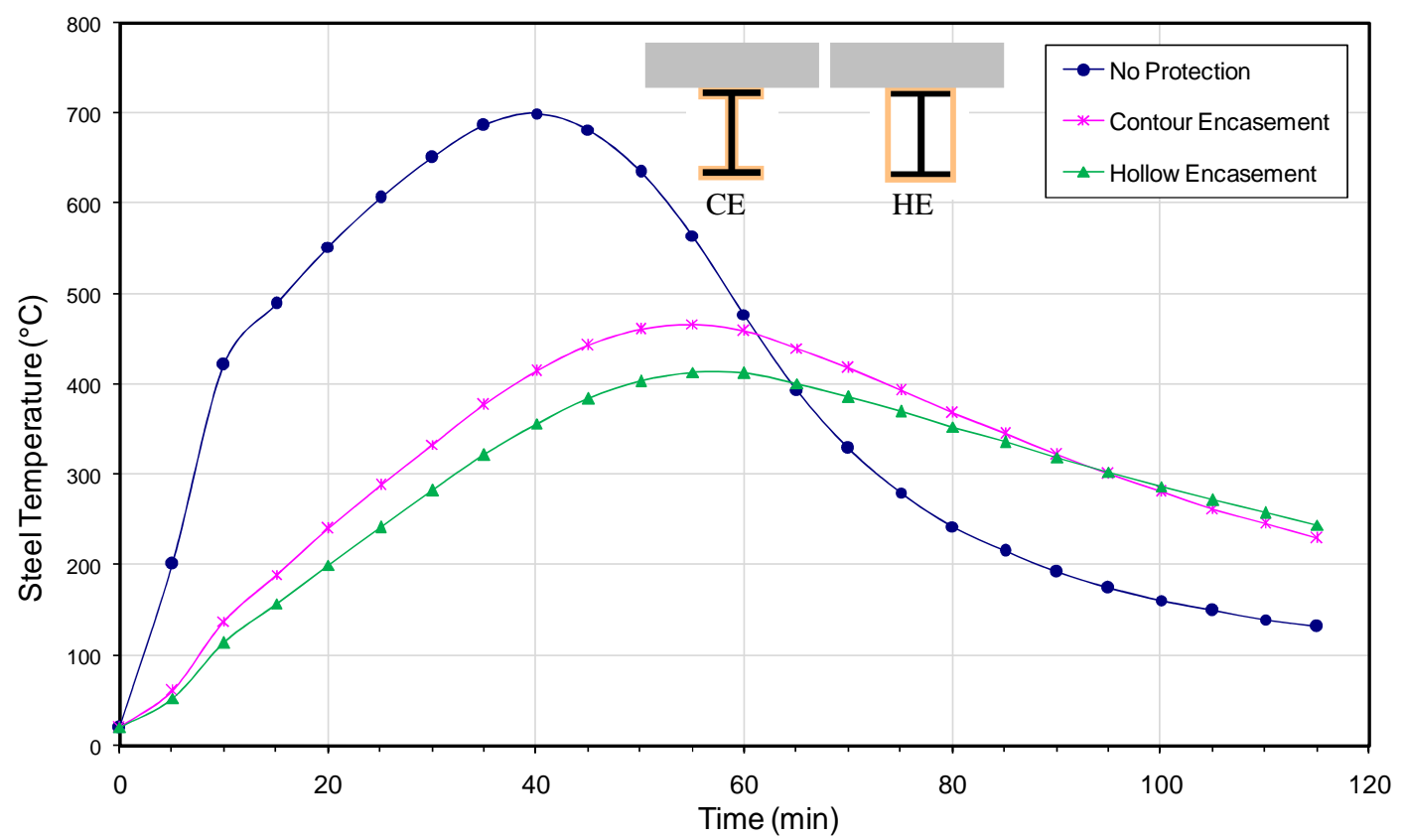

Fig. (20): Influence of protection shape on steel beam temperatures

\subsection{Influence of Protection Thickness and Type}

Figure (21) shows the effect of protection thickness on fire development of the steel beams. Four thicknesses having values of $5 \mathrm{~mm}, 10 \mathrm{~mm}, 15 \mathrm{~mm}$ and $20 \mathrm{~mm}$ of contour encasement spray mineral fiber protection were used in this study. A very clear trend is shown here, with more rapid fire development and earlier peak temperatures developed in case where small protection thickness is used. This is as expected, due to the more rapid heat transfer through small protection thickness. The results show that the peak temperature was reduced from $584{ }^{\circ} \mathrm{C}$ to $329{ }^{\circ} \mathrm{C}$ when the protection thickness increased from $5 \mathrm{~mm}$ to $20 \mathrm{~mm}$. The influence of different protection materials is illustrated in Fig. (22). All cases had $10 \mathrm{~mm}$ thickness of contour encasement protection shape. Results show that as the $k \rho c$ of the protection material increases, the steel temperature increases. This is because high $k \rho c$ means high conductivity and consequently higher steel temperatures. 


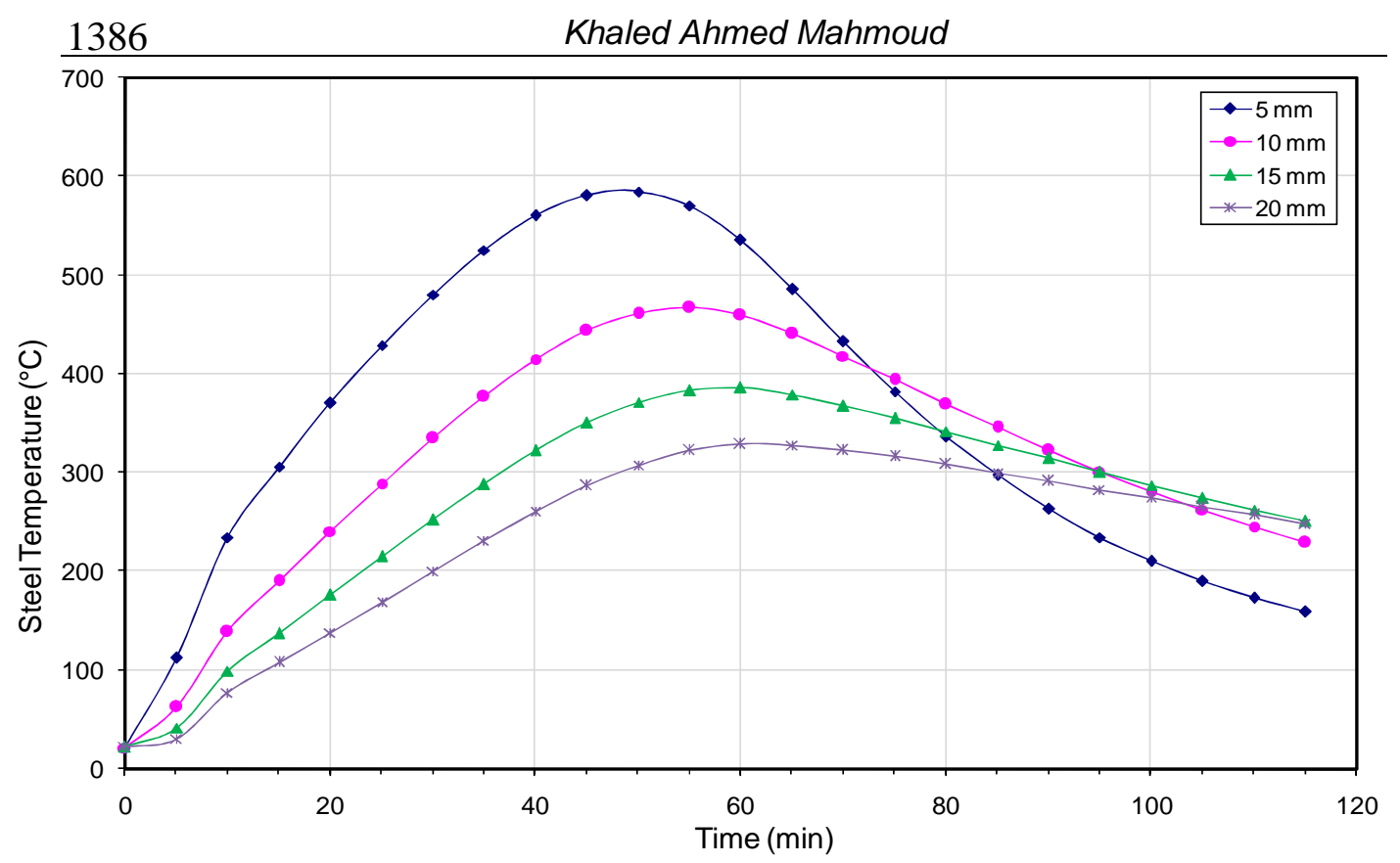

Fig. (21): Influence of protection thickness on steel beam temperatures

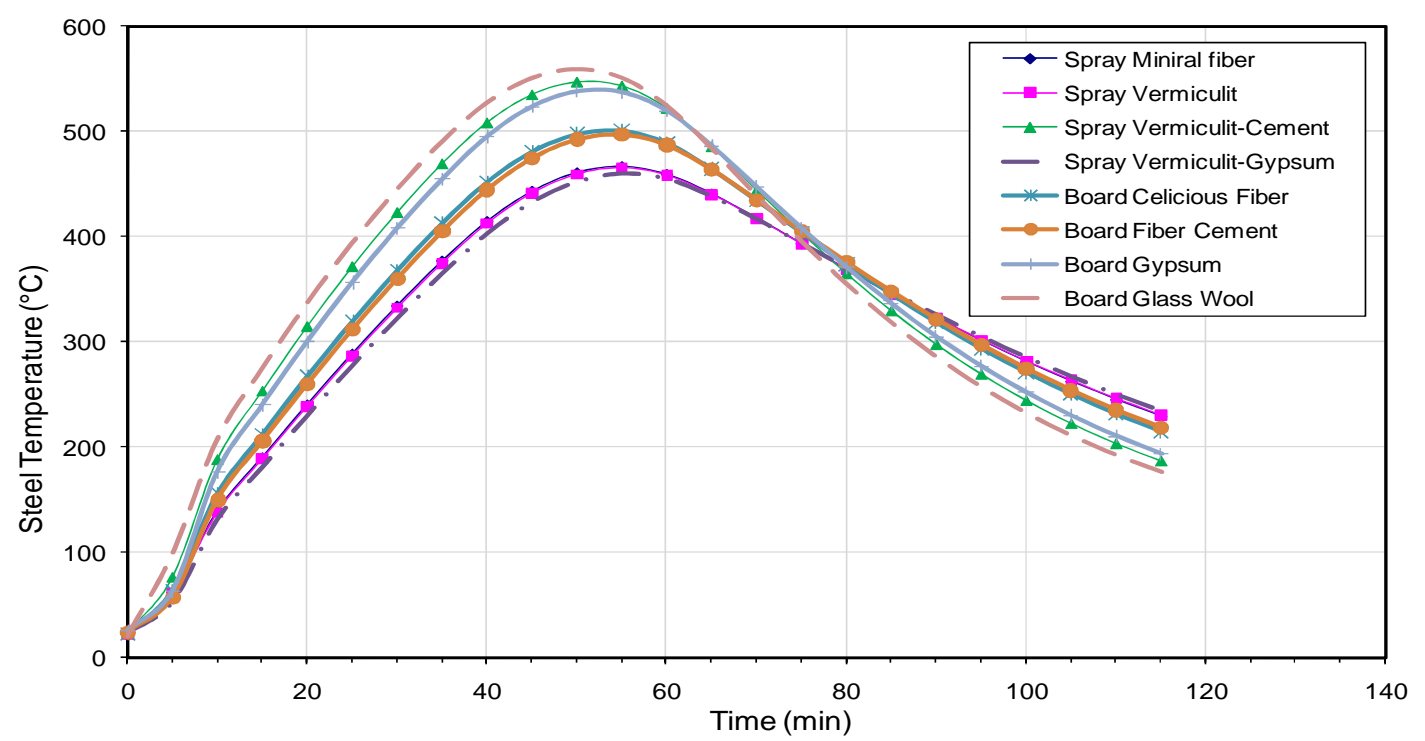

Fig. (22): Influence of protection type on steel beam temperatures

\section{FIRE RESISTANCE OF THE STEEL BEAMS}

Until recently $550{ }^{\circ} \mathrm{C}$ has been classified as the upper limit for steel temperatures in fire. Steel loses $40 \%$ of its room temperature strength by $550{ }^{\circ} \mathrm{C}$. For this reason protection has traditionally been applied to reduce the heating rate of steel so that it retains sufficient strength and stiffness during its prescribed period of fire resistance. Steel is an exceptionally good conductor thus reaches uniform temperatures when exposed to fire. At ambient steel has a thermal conductivity, $k$ of $54 \mathrm{~W} / \mathrm{mK}$ which 
decreases to half this value by $800{ }^{\circ} \mathrm{C}$. Beyond $800{ }^{\circ} \mathrm{C}$ it remains constant. The specific heat of steel at $20{ }^{\circ} \mathrm{C}$ is about $450 \mathrm{~J} / \mathrm{kgK}$ increasing to $700 \mathrm{~J} / \mathrm{kgK}$ at around $600{ }^{\circ} \mathrm{C}$. At $730^{\circ} \mathrm{C}$ steel undergoes a chemical transformation from ferrite-pearlite to austentite. This is associated with a huge increase in specific heat. The specific heat of steel seems to be independent of the grade of the steel [5]. The density of steel is approximately $7850 \mathrm{~kg} / \mathrm{m}^{3}$ decreasing slightly with increasing temperature

In OZONE model, The fire resistance of members is determined based on the assumptions stated in ENV 1993-1-2, and 2.4.4 [27].

For the compartment shown in Fig. (6), the steel beams in the roof are designed to resist an additional dead load of $200 \mathrm{~kg} / \mathrm{m}^{2}$, and live load is $200 \mathrm{~kg} / \mathrm{m}^{2}$. The fire resistance for steel beams was calculated by the model for four cases. Unprotected steel beam, protected steel beam using $5 \mathrm{~mm}, 10 \mathrm{~mm}$ and $15 \mathrm{~mm}$ spray mineral fiber protection. The results are shown in Fig. (23).

The results shows that for unprotected beam, the fire resistance is $13.1 \mathrm{~min}$. in case of protected beam with $5 \mathrm{~mm}$ protection thickness, the fire resistance is $25.8 \mathrm{~min}$ which represents approximately twice the fire resistance of unprotected beam case. When the protection thickness increases to $7.5 \mathrm{~mm}$, the fire resistance is $43.9 \mathrm{~min}$. for $10 \mathrm{~mm}$ protection thickness, the fire resistance is ore than $120 \mathrm{~min}$ which is the limit of fire course in this study.

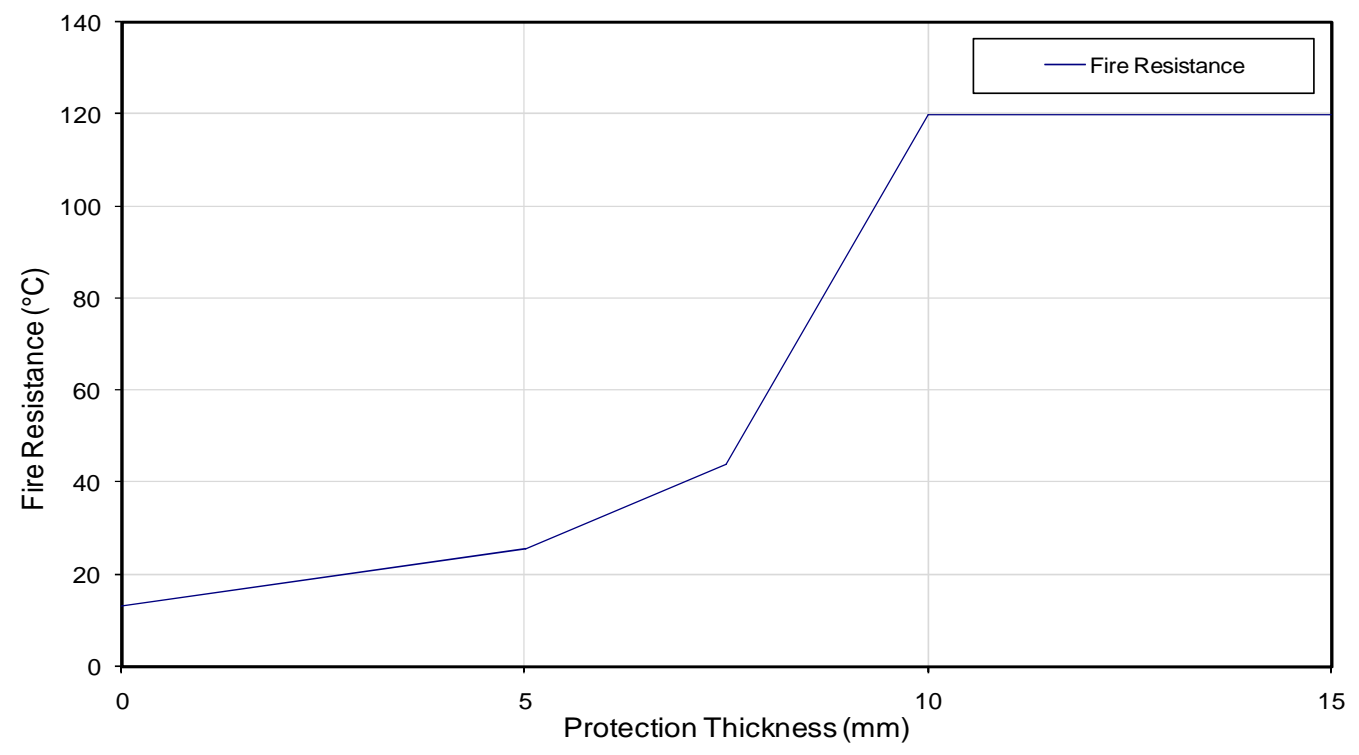

Fig. (23): Influence of protection thickness on fire resistance of steel

\section{CONCLUSIONS}

- An investigation has been performed by which the behavior of steel beams in a compartment building under natural fire conditions was analyzed. The OZONE fire model has been employed in order to predict the temperature development in the fire compartment. The influence of the important parameters on the steel beams temperature has been studied and the fire resistance of the steel beams was predicted. 
- The OZONE model for providing structural safety in case of compartment fire is quite realistic as it takes account of real fire characteristics and of existing active fire fighting measures. It can estimate the real behavior of a structure subjected to the natural fire which may arise under those real fire conditions. The consideration of real actions leads to real safety and also to optimized economy.

- The fuel or fire area play an important role in the fire scenario and consequently in steel beam temperature. As the fuel area increases the fire continues for longer time causing a higher temperature in the steel beams.

- Applying active fire fighting measures such as fire detection, alarm, automatic alarm transmission to the fire-fighters, smoke exhaust systems and sprinklers, provides protection to people that safety of people is ensured in an optimal way. When the active measure used properly, the fire can be under control and the steel beam temperature can be kept under the critical steel temperature which improve the fire resistance of the steel member.

- The amount of ventilations affects the peak temperature of the steel beams that by increasing the area of openings the amount of oxygen increases and consequently the steel temperature increases.

- Compartment dimensions affect the gas and steel beams temperature that the gas and steel beams temperature increases by increasing the compartment height or compartment floor area.

- The wall type and thickness affect the temperature inside the compartment that according to the wall thermal properties and wall thickness, the amount of heat transfer through the wall changes which may reduce the temperature inside the compartment.

- The passive protection by insulation and its thickness, strongly affects the temperature and fire resistance of steel beams. It reduces the steel beam temperature to fulfill the fire requirements of 90 minutes and more.

\section{REFERENCES}

1. Johnson P.F. "International developments in fire engineering of steel structures", Journal of Constructional Steel Research, 46, 415 (1998).

2. ISO, "General principles on reliability for structures", 84, 85, (1998).

3. British standards Institution, BS 476: Fire tests on Building Materials and Structures, Part 20-23, (1987).

4. Magnussun S.E. and Thelandersson S., "A discussion of compartment fire", Fire technology, 27, (1980).

5. Malhotra H.L., "fire resistance verses fire behavior" Fire Prevention, 134, 21-27, (1980).

6. Drysdale D. D., “The flashover phenomenon”, Fire Engineers Journal, pp. 18-23, (1996).

7. Kruppa J., Joyeux D. and Zhao B., "Scientific background to the harmonization of structural Eurocodes", HERON, Vol. 50, No. 4, (2005).

8. Van den Berg G., Fellinger J., Steenbackers P., Van overbeek T., "Multi-storey steel framed buildings under natural fire conditions", HERON, Vol. 50, No. 4, (2005). 
9. Jones W. W., Peacock R.D., Froney G.P. and Reneke P/A., "Consolidated model of fire growth and smoke transport CFAST", Version 6, NIST Special Publication 1026, (2006).

10. Gérardy J-C., "Sustainable steel buildings through Natural Fire Safety Concept", CTBUH 8th World Congress, (2008).

11. Schleich, J_B., "Performance Based Design for the Fire Situation, Theory and Practice", NSCC, (2009).

12. Konecki M. and M. Półka M., " Simple fire model for comparative studies of critical conditions during combustion of chosen polymer materials", Journal of Civil engineering and Management, 15(3), 247-257, (2009).

13. Olenicks S.M. and Carpenter D.J., "An updated international survey of computer models for fire and smoke", Journal of Fire Protection Engineering, Vol. 13, May (2003).

14. Tsuchiya Y. and Sumi K., "Computation of the behaviour of fire in an enclosure", Computation and Flame, 16, 131-139, (1971).

15. Buchanan A.H., "Fire engineering for a performance based code", Fire Safety Journal, 23, 1-16, (1994).

16. Thomas I.R and Bennetts I.D., "Fire in enclosures with single ventilation openings: Comparison of long and wide enclosures", In $6^{\text {th }}$ International symposium of Fire Safety Science, 941-952, (1999).

17. Kibry B.R. and Wainman D.E., "The behaviour of structural steel work in natural fires: The temperature attained by unprotected structural steel work in natural fires", Technical report, British Steel, (1997).

18. Owens G.W. and Knowles P.R., editors, Steel Designer Manual, Blackwell Science, fifth edition, (1994).

19. Stroup D.W., "Using Field modeling to simulate enclosure fires", Chapter 8, Section 3, The SFPE handbook of Fire Protection engineering, $2^{\text {nd }}$ edition, (1995).

20. Schleich, J.B., L-G. and A-L. Cajot "Competitive steel buildings through natural fire safety concept", In Draft Final Report, Part 1 to 5, ECSC Research 7210$S A / 125,126,213,214,323,423,522,623,839,937, B-D-E-F-I-L-N L-U K$ \& ECCS, July (2000).

21. ARBED- LABEIN- TNO- CTICM - Universite de Liege- "Development of design rules for steel structures subjected to natural fires in Large Compartments", In Final report CEC Agreement 7210/ SA210, 317,517,618,832, February (1997).

22. Joyeux, D. "Demonstration tests in large compartment and car parks", In ECSC European research project, INC-02/410c-DJ/IM pp. 25 - CTICM - France, March (2002).

23. Cadorin, J.F., Pintea, D. and Franssen J.M., "The Design Fire Tool OZone V2.0 Theoretical Description and Validation On Experimental Fire Tests", 1st DRAFT, University of Liege, Belgium, June (2001).

24. Cadorin J.F. and Franssen J.M., "A tool to design steel elements submitted to compartment fires - Ozone V2 : Pre and post flashover compartment fire model", Fire Safety Journal, May, (2002).

25. CEC Agreement 7210-SA/125/126/213/214/323/423/522/623/839/937. "Competitive Steel Buildings through Natural Fire Safety Concept", Final report, March (1999). 
26. CEC Agreement 7210-PA/PB/PC/PE/PF/PR-060. "Natural Fire Safety ConceptFull Scale Tests, Implementation in the Eurocodes and Development of a User Friendly design tool", Draft final report, December (2000).

27. CEN "Design of steel structures - Part 1-2: General rules - Structural fire design", In EN1993-1-2 Eurocode 3, Brussels, (2004).

\section{دراسة بار امترية لارجات حرارة الكمرات الحديدية في الابنية المغلقة والمعرضة لسيناريوهات حرائق حقيقية}

في هذا البحث، تم دراسة سلوك الابنية المغلقة بعد تعريضها لسيناريو هات حر ائق حقيقية. تم

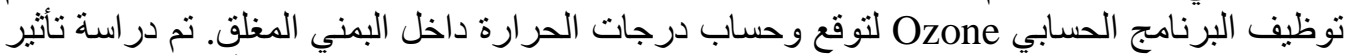

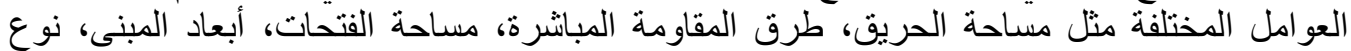

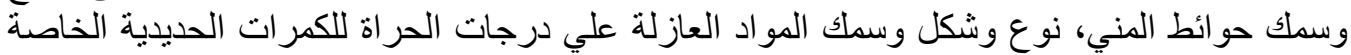
بسقق المبني. تم حساب مقاومة الحريق للكمر ات الحديدية لحالات مختلفة ونم مقارنة النتائج. 